Canadian

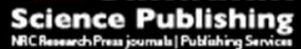

Canadian Journal of Forest Research Revue canadienne de recherche forestière

\title{
Detection and removal of disturbance trends in tree-ring series for dendroclimatology
}

\begin{tabular}{|r|l|}
\hline Journal: & Canadian Journal of Forest Research \\
\hline Manuscript ID & cjfr-2015-0366.R1 \\
\hline Manuscript Type: & Article \\
\hline Date Submitted by the Author: & 08-Dec-2015 \\
\hline Complete List of Authors: & $\begin{array}{l}\text { Rydval, Miloš; University of St Andrews, School of Geography \& } \\
\text { Geosciences; Czech University of Life Sciences Prague, Faculty of Forestry } \\
\text { and Wood Sciences } \\
\text { Druckenbrod, Daniel; Rider University, Department of Geological, } \\
\text { Environmental, \& Marine Sciences } \\
\text { Anchukaitis, Kevin; University of Arizona, School of Geography and } \\
\text { Development \& Laboratory of Tree Ring Research; Columbia University, } \\
\text { Lamont-Doherty Earth Observatory, Palisades } \\
\text { Wilson, Robert; University of St Andrews, School of Geography \& } \\
\text { Geosciences; Columbia University, Lamont-Doherty Earth Observatory, } \\
\text { Palisades }\end{array}$ \\
\hline Keyword: & $\begin{array}{l}\text { disturbance, Scotland, proxy system modelling, intervention detection, tree } \\
\text { rings }\end{array}$ \\
\hline
\end{tabular}

\section{SCHOLARONE \\ Manuscripts}


1 Detection and removal of disturbance trends in tree-ring series for dendroclimatology

3 Miloš Rydval ${ }^{1,2}$, email: mr268@st-andrews.ac.uk

$4 \quad$ Daniel Druckenbrod ${ }^{3}$, email: ddruckenbrod@rider.edu

$5 \quad$ Kevin J. Anchukaitis ${ }^{4,5}$, email: kanchukaitis@email.arizona.edu

6 and Rob Wilson ${ }^{1,5}$, email: rjsw@st-andrews.ac.uk

8 1. School of Geography and Geosciences, University of St Andrews, UK

9 2. Faculty of Forestry and Wood Sciences, Czech University of Life Sciences Prague, Kamýcká 10 129, Praha 6-Suchdol, Prague, 16521, Czech Republic

11 3. Department of Geological, Environmental, \& Marine Sciences, Rider University, 12 Lawrenceville, NJ, USA

134 School of Geography and Development \& Laboratory of Tree Ring Research, University of 14 Arizona, Tucson, AZ, USA

15 5. Lamont-Doherty Earth Observatory, Columbia University, Palisades, NY, USA 
Abstract

Non-climatic disturbance events are an integral element in the history of forests. While the identification of the occurrence and duration of such events may help to understand

31 environmental history and landscape change, from a dendroclimatic perspective, disturbance

32 can obscure the climate signal in tree rings. However, existing detrending methods are unable to

33 remove disturbance trends without affecting the retention of long-term climate trends. Here we

34 address this issue by using a novel method for the detection and removal of disturbance events

35 in tree-ring width data to assess their spatiotemporal occurrence in a network of Scots pine 36 (Pinus sylvestris L.) trees from Scotland. Disturbance trends 'superimposed' on the tree-ring 37 record are removed before detrending and the climate signals in the pre-correction and postcorrection chronologies are evaluated using regional climate data, proxy system model simulations, and maximum latewood density (MXD) data. Analysis of sub-regional chronologies from the West Highlands and the Cairngorms in the east reveals a higher intensity and more systematic disturbance history in the western sub-region, likely a result of extensive

42 timber exploitation. The method improves the climate signal in the two sub-regional chronologies, particularly in the more disturbed western sites. Our application of this method demonstrates that it is possible to minimise the effects of disturbance in tree-ring width chronologies in order to enhance the climate signal. 


\section{1. Introduction}

55

Non-climatic disturbance events represent an integral element of forest dynamics, and the identification of the occurrence and duration of such events using tree-ring data may serve to help understand environmental history and landscape change. The conceptual linear aggregate model (Cook 1985) of tree growth describes the production of the annual growth increment as the aggregation of multiple factors (eq.1).
eq.1:
$\mathbf{G}_{\mathrm{t}}=\mathbf{A}_{\mathrm{t}}+\mathrm{C}_{\mathrm{t}}+\delta \mathrm{D} \mathbf{1}_{\mathrm{t}}+\delta \mathrm{D} \mathbf{2}_{\mathrm{t}}+\mathbf{E}_{\mathrm{t}}$

where $G_{t}$ represents total growth, $A_{t}$ expresses the age-related growth trend, $C_{t}$ represents the climate trend, $\delta \mathrm{D} 1_{\mathrm{t}}$ is the endogenous tree specific disturbance internal to the local stand, $\delta \mathrm{D} 2_{\mathrm{t}}$ is exogenous disturbance impacting all trees within the stand, and $\mathrm{E}_{\mathrm{t}}$ is variance due to random processes, in year t. From a dendroclimatic perspective, it is clear that the presence of nonclimatic components such as disturbance could obscure the climate signal in tree-ring data. To achieve an understanding of climatic variability from tree rings it is necessary to isolate the desired climatic signal extant in tree-ring series while minimising the influence of other forcings such as disturbance. The removal of $A_{t}$ is typically achieved by detrending and since $E_{t}$ is presumed to occur randomly in time and between trees in a stand, its influence can be minimised by increasing replication. Endogenous disturbance $\left(\delta \mathrm{D} 1_{\mathrm{t}}\right)$ is spatially limited and results from internal stand dynamics while the origin of spatially more extensive exogenous disturbances $\left(\delta \mathrm{D} 2_{\mathrm{t}}\right)$ can for example include wind, fire and outbreaks of disease and insects. Removal of endogenous and exogenous components can be complicated as such trends can mimic climatic trends. However, the non-synchronous nature of endogenous disturbance trends within a stand represents a distinguishing feature that can serve to differentiate them from trends that reflect the wider scale influence of climate (Cook 1985). 
As part of the Scottish Pine Project (http://www.st-andrews.ac.uk/ rjsw/ScottishPine/), a network of 44 living Scots pine (Pinus sylvestris L.) sites were sampled from semi-natural pine woodlands throughout northern Scotland (Figure 1). Through the development of this living tree network, a distinct difference was observed between trends in detrended ring width (RW)

81 chronologies from sites primarily located in the west of the Scottish Highlands and sites in the Cairngorms. The trend differences are apparent when standard detrending approaches are applied to create sub-regional composite chronologies (Figure 2). We hypothesise that these differences are not related to varying climates between the two sub-regions, but rather are predominantly related to the influence of growth changes due to disturbance events occurring through time. These disturbance events are most likely related to past anthropogenic woodland exploitation and clearance (Smout et al. 2005; Steven and Carlisle 1959). As Scots pine is a shade intolerant species (Gaudio et al. 2011), it should be possible to detect growth releases as a result of canopy opening due to felling. Temporary increases in nutrient availability from logging residue (Hyvönen et al. 2000; Palviainen et al. 2004) and decreased competition

91 following the clearance of neighbouring trees (Valinger et al. 2000) may also enhance this 92 effect. trends, they cannot do so without affecting the retention of long-term climate trends. For example, standard detrending approaches (e.g. negative exponential or linear functions) commonly used to detrend RW data cannot model and remove shorter term growth releases related to disturbance leading to biases in the final chronologies. Although it may be possible to remove disturbance-related trends from RW series with the use of more flexible detrending approaches such as cubic smoothing splines (e.g. Cook and Peters 1981), this approach will also 100 remove multidecadal and longer term variability, which is undesirable for reconstructing past 101 climate as such trends may represent climatic variations. As disturbances bias the mid- to low- 
102 frequency components of a RW chronology, the presence of non-climatic (disturbance) trends

103 needs to be addressed if RW data are to be used for dendroclimatic reconstruction. A possible

104 solution is to identify disturbance in the RW record, quantify the contribution of these events to 105 radial growth, and then attempt to isolate and remove these influences.

\subsection{Detecting Disturbance}

Detection of disturbance signatures in tree-ring data has received considerable attention in the context of a wide range of factors including natural and anthropogenic sources of

110 disturbance such as wind and storm events (e.g. Foster 1988; Nagel et al. 2007; Svoboda et al. 111 2014), insect and pathogen outbreaks (e.g. Speer et al. 2001; Veblen et al. 1991), forest fires 112 (Swetnam 1993), snow avalanches (Veblen et al. 1994), flooding (Yanosky and Jarrett 2002),

113 forest stand dynamics (Fraver et al. 2009), environmental pollution (e.g. Elling et al. 2009; 114 Rydval and Wilson 2012; Savva and Berninger 2010; Wilson and Elling 2004), timber 115 harvesting, and woodland clearance (Bebber et al. 2004; Nowacki and Abrams 1997). A 116 common approach to disturbance detection is based on the statistical identification of 117 disturbance events manifested as either growth suppression or releases in the RW record with 118 duration of one or more years to several decades.

119 In ecological studies, disturbance detection methods have typically relied on the 120 identification of growth changes determined either as absolute changes (Čada et al. 2013; Fraver 121 and White 2005) or more commonly as relative (percent) changes (Nowacki and Abrams 1997;

122 Pederson et al. 2008; Svoboda et al. 2014) in growth to identify prolonged periods of growth 123 release or suppression by comparison with periods of growth immediately prior to the initiation 124 of the disturbance event. Increasingly sophisticated approaches include or specify additional 125 detection criteria or data characteristics (e.g. Speer et al. 2001), accounting for a range of 126 variables related to growth release or developing more adaptable release threshold criteria 
127 (Black and Abrams 2003). A set of specific growth release criteria were developed by Lorimer

128 and Frelich (1989) and were later adapted by Nowacki and Abrams (1997) to permit the

129 detection of multiple events in a single sample. By assessing the percent growth change using

130 10-yr radial growth averages prior to and following each year of growth, their approach also

131 attempted to minimise the likelihood of falsely detecting climate-related variability as

132 disturbance releases (Nowacki and Abrams 1997).

133 The use of boundary-line release criteria offers a more flexible and adaptive method for

134 the establishment of disturbance-related growth release thresholds by scaling releases according

135 to the maximum physiological potential as determined by previous growth rates which are

136 species-specific and may also vary regionally or locally (Black and Abrams 2003). While the

137 possibility of applying more unified release criteria to a range of species in order to facilitate

138 both cross-species and between-site comparisons was proposed by Black and Abrams (2004),

139 the development of species-specific boundary-line functions is normally necessary, although a

140 single (universal) boundary line can be developed and applied over the range of some species

141 (Nagel et al. 2007). A detailed comparative review of disturbance detection methods was

142 presented by Rubino and McCarthy (2004). While such methods are capable of identifying

143 growth release events with varying success, they all lack the ability to remove disturbance

144 trends from tree-ring records.

145

146

\subsection{The Combined Step and Trend Method}

Druckenbrod (2005) and Druckenbrod et al. (2013) developed a robust procedure to 148 detect disturbances called Combined Step and Trend Intervention Detection (CST) which

149 accounts for temporal autocorrelation and age-related growth trends in ring-width data. The

150 CST method employs a time series analysis approach for the identification of 'interventions' (i.e.

151 external forcings that affect a time series and that can be detected as outliers from a model of 
152 that time series) manifested as either step outliers or trend changes. The method has been shown

153 to successfully identify instances of known disturbance, and the potential application of 154 intervention detection to a range of species and growth environments has been proposed 155 (Druckenbrod 2005; Druckenbrod et al. 2013). Intervention detection methods offer the 156 capability to not only identify and assess the timing, duration and magnitude of growth 157 attributable to disturbance, but also to quantify the contribution of these events to the RW record 158 and remove their influence from the time series.

159 Druckenbrod et al. (2013) suggested that the removal of disturbance signals from RW 160 series using an intervention detection approach could be applied to enhance the climate signal. 161 Here for the first time we apply intervention detection in this manner. The application of this 162 approach to RW chronologies from the Scottish Highlands offers an opportunity to evaluate its 163 performance on an extensive network of sites without detailed a priori knowledge of the history 164 of past disturbance but in a region where substantial timber extraction has taken place over the 165 last five centuries. We use a variant of the CST method to detect and remove the disturbance 166 'noise' superimposed on the climate signal and evaluate the spatio-temporal occurrence of 167 disturbance events in RW chronologies from the Scottish pine network. We assess the climate 168 signal in the pre- and post-correction chronologies using both simulated chronologies from the 169 VS-Lite (Tolwinski-Ward et al. 2011) proxy system model and regional instrumental 170 temperature data. We further evaluate differences between the corrected and uncorrected RW 171 chronologies by comparison to a maximum latewood density (MXD) composite chronology 172 from multiple sites across northern Scotland, which should represent a purer summer 173 temperature signal not significantly affected by disturbances. 
2 Materials and Methods

178

179

180 181 from the International Tree-Ring Data Bank originally used in Hughes et al. (1984) to 182

\subsection{Sampling sites and tree-ring data}

The entire network of 44 RW Scots pine chronologies from the Scottish Highlands was utilised in this study (Figure 3.1). Seven of these chronologies were supplemented with RW data reconstruct Edinburgh summer temperatures (ITRDB - Grissino-Mayer and Fritts 1997; ITRDB, 2014). The Scottish regional maximum latewood density (MXD) chronology was developed from 12 individual site chronologies (7 of which included MXD data archived in the ITRDB). A summary of individual site and chronology information is listed in Table 3.1. Two sub-regional clusters were defined for the Cairngorms National Park (including the southeast Highland site 'Drimmie' - hereafter referred to as 'Cairngorms') and the sites stretching from the SW to the NW Highlands (hereafter referred to as 'West'). For RW measurement, following standard dendrochronological practice (Stokes and Smiley 1968), samples were air-dried, mounted,

sanded and visually crossdated before measurement. Samples were measured to a precision of $0.001 \mathrm{~mm}$ with either a Velmex traversing measuring stage or CooRecorder (Larsson 2014) from scanned sample images. With the exception of the 'older' ITRDB archived data, measurement of MXD followed the procedures described in Rydval et al. (2014). Crossdating was statistically validated using COFECHA (Holmes 1983) and CDendro (Larsson 2014).

\subsection{Intervention detection and disturbance correction}

The procedure employed for disturbance identification and correction follows Druckenbrod et al. (2013) and is briefly outlined below. Before detrending, power transformation (Cook and Peters 1997) of the measurements was performed in order to reduce heteroscedasticity in the RW series (or in other words, to limit the increase in spread of the data with increasing level). The transformed measurement series were then detrended by fitting 
202 either negative exponential or linear regression functions. Negative exponential curves are fitted 203 iteratively from the beginning of the transformed measurement series and the curve length with 204 the lowest mean squared error was selected to approximate $A_{t}$. This detrending approach 205 removes the age trend for a RW series that would otherwise fail to fit a negative exponential 206 curve due to a release event later in that RW series. The order ( $p$ ) of the autoregressive (AR) 207 model, which best fits each series and AR model parameters were determined according to the 208 maximum entropy 'Burg' method (Barnard 1975). A residual time series from the AR model 209 estimates and the detrended series were calculated. Inverse modelling was applied for the first 210 ' $p$ ' indices to permit the calculation of residuals for the full length of the series. Values of years 211 with missing rings were estimated using 1-step ahead AR model predictions. Running means of 212 the residual series with varying window lengths (between 9 and 30 years) were used for outlier 213 detection. As the distribution of these running means should approach a Gaussian distribution, it 214 is possible to identify residual means beyond a specified threshold as outliers from this 215 distribution. Tukey's bi-weight mean and scale (robust equivalent of standard deviation) were 216 used to give more robust measures as some distributions may only approximate a Gaussian 217 distribution. A sequence of residuals was identified as an outlier when it exceeded a scale of 2183.29 from the bi-weight mean. From all sets of detected outliers using a range of window 219 lengths, the largest outlier was used to determine the first year of the intervention and also the 220 window length which can be used to best characterise it. The disturbance trend was then 221 removed, the AR model re-determined and the entire process was iteratively repeated until no 222 outliers were detected. In the CST method, removal of the disturbance trend is performed by 223 fitting a linear regression to the outlier period. Additional details pertaining to the CST approach 224 are described in Druckenbrod et al. (2013).

225 On occasion, the CST method may produce negative measurement values in parts of 226 series when they are expressed in original measurement units after disturbance correction. Since 
negative measurements are illogical, all such values are treated as if no growth occurs (i.e. zero growth). This leads to a possible loss of information and also creates a potential problem when attempting to detrend series corrected with CST. For example, ARSTAN (Cook and Holmes 1986) is widely used for detrending tree-ring measurement data. However, the programme does

231 not permit fitting a detrending function to measurements if this function were to be negative at 232 any point. Even with power transformed series, this issue can occur with series which approach 233 or reach 'zero' measurement values. Although it is possible to utilise the transformed / detrended 234 versions of the CST-corrected series for further analysis without the need to re-express these in 235 original measurement units, this would prevent the application of alternative detrending 236 approaches (which may be of particular importance for dendroclimatological analysis) other 237 than the one currently integrated within the CST procedure as described above. Although it is 238 possible to remove series that exhibit such characteristics (i.e. containing a series of zero 239 measurement values), this would not be desirable since $\sim 5-10 \%$ of series may typically be 240 affected and their exclusion would therefore lead to further removal of valuable information. As 241 an alternative approach, a constant of $1 \mathrm{~mm}$ was added to all measurements prior to 242 commencing the disturbance detection procedure in order to avoid the above-mentioned issues. 243 Although this 'shift' results in a variance reduction of the detrended chronologies, there is little 244 difference between the transformed and untransformed chronologies, with the overall trends 245 remaining unaffected (Rydval 2015). The shifted versions of both the pre-correction (pre-CST) and post-correction (post-CST) chronologies were used in all subsequent analysis.

248 versions of CST used a two-step process to remove disturbance trends and would on occasion 249 introduce an artificial trend if only the first step was performed, which could ultimately affect 250 the overall structure and trends in a site chronology and would certainly affect attempts to 251 develop for example a regional standardisation curve (Briffa and Melvin 2011). Unlike those 
252 earlier versions, the modified method used here features an improved curve-based disturbance 253 trend removal mechanism (Warren 1980), which we use to remove disturbance release events in 254 a single step. This adjusted version is referred to here as 'curve intervention detection' (CID). 255 CID resolves the two-step disturbance trend removal issue altogether by correcting for the 256 growth release in a single step using indices with a mean of 1 . After correction, the time series 257 data are re-expressed as raw (non-detrended) measurements after the original growth trends are 258 added to the disturbance-corrected data. In this way, a range of detrending approaches can be 259 applied to both the pre- and post-CID corrected measurement series using commonly utilised 260 detrending packages (e.g. ARSTAN - Cook and Holmes 1986).

261 It should be noted that the initiation of disturbance-related growth releases as they are 262 detected may not reflect the actual initiation year precisely (Druckenbrod et al. 2013). Also, the 263 timing of the response to a disturbance event may differ between individual trees as some may 264 react earlier than others. For these reasons and also in the interest of simplifying interpretation, 265 rather than presenting detected disturbance events on an annual scale, disturbance initiation 266 years are grouped and presented according to the decade in which they were detected.

\subsection{Chronology development}

All series (pre- and post-CID) were detrended using Signal Free (SF) detrending (Melvin and Briffa 2008), which was developed with the intention to limit chronology trend distortion

271 resulting from commonly applied standardisation procedures. Essentially, the procedure 272 removes the common (climatic) signal, which may otherwise bias the fitting of the detrending 273 functions. SF detrending was performed by fitting negative exponential or negative linear 274 functions to the series. Indices were calculated as ratios by division and variance stabilisation 275 (Osborn et al. 1997) of the time series was performed to minimise artificial variance changes in 276 chronology variance primarily as a result of changing sample size, particularly when sample 
277 size is low. Tukey's robust bi-weight mean was used to limit the influence of outliers on the

278 final mean index calculation (Cook and Kairiukstis 1990). An alternative, non-SF detrending

279 approach was also explored using the more conventional negative exponential or linear

280 functions with negative slope (NX) in ARSTAN (Cook and Holmes 1986) with indices

281 calculated as residuals after power transformation. Analysis using NX chronologies produced 282 broadly similar though generally weaker results (results not shown).

\subsection{Assessing CID correction}

In order to assess chronology changes resulting from disturbance trend removal and more specifically to ascertain whether improvement of the RW chronology climate signal had occurred, three separate approaches were utilised;

\subsubsection{Correlation with instrumental data}

Following the procedure in Rydval et al. (2014), mean monthly surface temperatures for Scotland (MST) by Jones and Lister (2004), were extended to 2009 using CRU TS3.10 mean extended MST data are hereafter referred to as the EMST dataset. The correlation between EMST temperatures for the January-through-August (Jan-Aug) season (for which both subregions show a consistently strong response) and sub-regional or individual site chronologies is used to assess the climate signal in the pre- and post-CID chronologies.

\subsubsection{VS-Lite growth modelling:}

The application of growth simulation modelling can provide insight into observed

300 growth by the production of a synthetic record of expected growth behaviour based on climatic 301 forcing alone (Evans et al. 2013). Derived from the Vaganov-Shashkin (VS) model (Vaganov et 
302

303

304

305

306

307

308

310

311

312

313

al. 2006), VS-Lite (Tolwinski-Ward et al. 2011) is a streamlined, monthly resolution processbased proxy system model of tree-ring growth. The model allows for non-linear and nonstationary climate influences on tree growth, and therefore permits greater complexity than linear empirical statistical approaches to growth modelling (Tolwinski-Ward et al. 2011; Tolwinski-Ward 2012). The model requires monthly precipitation and temperature data, and its relative simplicity offers the potential for extensive application. VS-Lite utilises only 12 model parameters compared to over 40 for the full VS model.

The model has been validated over a wide range of species, climate regimes and biomes (Tolwinski-Ward et al. 2011; 2013; 2014). Analysis of differences between actual and modelled RW data has distinct advantages over evaluating chronology performance by its response to instrumental climate data. Specifically, simulated growth is controlled by the climatic variable (temperature or precipitation, which determines moisture availability) that is the most limiting for a particular year's annual growth. The growth response of RW data simulated by VS-Lite need not be constrained to reflect a particular seasonal window as the integration of annual growth is primarily driven by input climate data and the length of the growth season and the contribution to annual growth from individual months can vary between years.

Using VS-Lite, simulated chronologies were generated for the 1901-2009 period for each site using site latitude and mean monthly CRU TS3.10 gridded $0.5^{\circ}$ temperature and precipitation data (Harris et al. 2014) overlapping with the location of each site. Gridded temperature data were adjusted for site elevation (Mr Ian Harris, pers.comm., 2013). Two subregional composite chronologies 'Cairngorms' and 'West', were also compared against VS-Lite simulations developed using an average of the gridded climate data covering each of the subregions. The average of the locations of all sites within each sub-region was used to determine the input latitude for the sub-regional models. 
Model parameters and their settings used in this analysis are listed in Table 3.2 and a

327 detailed description is available in Tolwinski-Ward et al. (2011), which also includes a general

328 overview of VS-Lite functionality. Monte Carlo simulations (2500 iterations) were carried out

329 by incrementally varying the VS-Lite minimum and optimal growth parameters for temperature

$330\left(T_{1}, T_{2}\right)$ and soil moisture $\left(M_{1}, M_{2}\right)$ within the parameter range provided in Table 3.2. The

331 optimal or 'best' models were selected based on highest correlation with individual site or sub-

332 regional chronologies.

333

\subsubsection{Comparison with MXD chronology}

The previous two methods do not provide any assessment of the pre- and post-CID

336 chronologies before 1866 and 1901 respectively. As individual MXD site chronologies possess

337 a consistently stronger climate signal and are less variable between sites, it is therefore assumed

338 that they are either not affected at all by disturbance or are at least systematically less affected

339 than RW. Therefore, as an additional assessment of the RW chronologies, the correlation

340 between each pre- and post-CID chronology is calculated (for periods with replication $\geq 10$

341 series) against a composite MXD chronology utilising data from 12 Highland sites (Figure 3.1

342 and Table 3.1) extending over the period 1713-2009.

343 The MXD composite chronology was developed by fitting negatively sloping linear

344 functions to the MXD series with the application of SF detrending. Detrended indices were

345 calculated as residuals of the measured series and the fitted curves. To produce the MXD

346 chronology, the bi-weight mean of the series indices was calculated and chronology variance

347 was stabilised using a 51 year window to account for changing sample replication and mean

348 inter-series correlation (RBAR) over time. 


\section{Results}

\section{$352 \quad 3.1$ Sub-regional disturbance timeline}

353 The incidence of identified disturbances in the Highlands is summarised in Figure 3 for 354 each decade (see Supplementary Information for individual site chronology disturbance 355 assessment). These results represent the sub-regional scale history of years in which the 356 initiation of disturbance related growth releases was detected. Even though sample replication in 357 the West Highlands remains lower than that of the Cairngorms during most periods, the absolute 358 number of identified events is greater in the former, particularly during the early $18^{\text {th }}$ to mid-19 359 centuries.

By adjusting for changes in replication, a clearer comparison of disturbance frequency

361 can be determined (Figure $3 \mathrm{~b}$ ). With the exception of the mid-17 $7^{\text {th }}$ century the proportion of 362 disturbance events remains consistently higher in the West until $\sim 1860$. Thereafter, the 363 proportion of disturbance events decreases to a lower level and remains similar for both sub364 regions. A significant correlation $(\mathrm{r}=0.36, \mathrm{p}=0.022)$ between the Cairngorms and West 365 disturbance frequency histograms in Figure 3b was observed for the 1600-1999 period. This 366 relationship was found to be stronger when only the periods $1700-1999(\mathrm{r}=0.67 ; \mathrm{p}<0.001)$ and 367 1800-1999 $(\mathrm{r}=0.73 ; \mathrm{p}<0.001)$ were considered. Using first-differenced data the correlations 368 were $(\mathrm{r}=0.58, \mathrm{p}<0.001 ; \mathrm{r}=0.58, \mathrm{p}=0.001 ; \mathrm{r}=0.56, \mathrm{p}=0.011)$ for the three periods, 369 respectively.

Replication-adjusted chronologies of the mean size of disturbance-related growth

371 releases provide an indication of the mean amount of additional increment growth attributable to 372 disturbance releases (Figure 3c). The results provide further indication that, overall, sites in the

373 West Highlands experienced relatively more disturbance-related growth release, particularly 374 throughout the $19^{\text {th }}$ century. A further notable difference is the presence of higher magnitude 375 shorter-term growth release pulses in the West, which do not occur to the same extent or degree 
in the Cairngorms network. Comparing the mean size of growth releases in the West and

377 Cairngorms demonstrates that the magnitude of the growth release remains similar for both sub-

378 regions with the exception of the mid- $18^{\text {th }}$ and the $19^{\text {th }}$ century when the average size of released

379 growth is greater in the West (Figure 3d).

380

\subsection{Pre- and post-CID comparison with instrumental, VS-Lite and MXD data}

The seasonal response of the Cairngorms and West RW chronologies to temperature

(based on average results of individual site chronologies in each sub-region) is primarily

weighted to the July to August summer season, although a broader winter-summer seasonal

response from January or December of the previous year until August is also seen (Figure 4).

The pre-CID response of the Western composite is considerably weaker than that of the

Cairngorms. However, while the response of chronologies from both sub-regions improves after

CID correction, the degree of post-CID improvement is much greater for the West.

The general post-CID improvement in the correlations between chronologies and

gridded instrumental temperature data is illustrated in Figure 5. In general, greatest

improvement is observed with the West chronologies while there is little overall change in the

pre- and post-CID Cairngorms chronologies, although the extent of the changes varies from site

to site. While correlations for some sites are lower after CID correction, these poorer results are

mostly slight in nature and generally involve sites that already display reasonably high pre-CID

correlations. Despite minor differences, primarily in the absolute magnitude of the relationship,

the correlation changes between simulated VS-Lite chronologies and real pre- and post-CID site

397 chronologies (also presented in Figure 5) overall agree with and support in their sign and

398 magnitude the correlation changes identified with the instrumental temperature data.

Sub-regional chronologies of the Cairngorms and West Highland sites (Figure 6a) 
401 chronologies lasting more than a decade occur in the early $18^{\text {th }}$ century, mid- to late $19^{\text {th }}$ century 402 and after $\sim 1970$. Correlations with the ESMT January-August mean temperature over the 18664032009 period indicate that overall the West Highland chronology expresses a weaker climate 404 signal $(r=0.37)$ than the Cairngorms chronology $(r=0.62)$. Periods when differences occur 405 between the regional chronologies coincide with patterns of disturbance release in Figure $3 \mathrm{c}$ and 406 particularly events in the mid- $19^{\text {th }}$ century.

The comparison of pre- and post-CID chronologies (Figure 6b-d) demonstrates that differences in the Cairngorms chronology before and after correction are minimal. However, a more extensive transformation is observed with the West chronology. Among the most apparent 410 post-CID differences in the West chronology are the lower mid-19 ${ }^{\text {th }}$ century indices and also 411 higher index values in the late $20^{\text {th }}$ century. Increases in index values additionally occur in the 412 early $18^{\text {th }}$ century and around 1800 . These changes also translate to a considerable improvement 413 in the correlation with instrumental temperature data between 1866 and $2009\left(\mathrm{r}_{(\text {pre-CID) }}=0.37\right.$; $\left.414 \mathrm{r}_{(\text {post-CID) }}=0.58\right)$. Greater similarity between the Cairngorms and West chronologies after CID 415 correction over the $1650-2010$ period is also observed $\left(\mathrm{r}_{(\text {pre-CID })}=0.64 ; \mathrm{r}_{(\text {post-CID })}=0.72\right)$.

416 Comparison of real Cairngorms and West sub-regional chronologies against 417 chronologies simulated by VS-Lite (Figure 7) reinforce the findings of the chronology 418 assessments performed using instrumental temperature data (Figure 6). The Cairngorms 419 chronologies before and after CID correction are nearly identical with no statistically significant 420 change in agreement against the 'best' VS-Lite model $(r=0.60$ and $r=0.62$ against model 421 output, respectively). More extensive changes to the trend of the post-CID West chronology 422 (specifically the lower post-CID values around 1940 and a more positive trend from $\sim 1970$ 423 onwards) result in considerably better agreement with the VS-Lite model simulation $(\mathrm{r}=0.48)$ 424 compared to the pre-CID results $(r=0.26)$. 
In addition to including correlation changes with instrumental temperatures (also

426 presented graphically in Figure 5), changes in the correlation between individual site RW

427 chronologies and the Scotland MXD composite chronology are presented for the Cairngorms in

428 Table 3 and for the West in Table 4. Correlation changes of RW chronologies evaluated with the

429 VS-Lite simulations were not included in this assessment because overall results were similar to

430 the instrumental temperature assessment as was already noted in relation to Figure 5. Regardless

431 of the actual direction of the change, when comparing the RW chronology correlations with

432 ESMT temperature and with the MXD chronology, there is general agreement in the direction of

433 change (either correlation increase or decrease) in 21 out of 27 of the Cairngorms chronologies

434 (Table 3). When considering correlation change results of the West chronologies (Table 4),

435 there is agreement in 15 out of 17 chronologies, which is proportionally more than for the

436 Cairngorms.

\section{Discussion}

\section{$439 \quad 4.1$ Disturbance patterns}

Although disturbance events were detected in the Cairngorms chronologies, the number

441 of identified interventions are far fewer, less clustered and temporally more evenly spread out

442 than in the West. Although a few individual sites such as Loch Gamnha (LG) showed

443 considerable post-CID improvement, minor changes to the overall Cairngorms chronology after

444 CID correction (Figure 6a) suggests limited influence of disturbance on the climate signal in this

445 sub-region, which is also supported by comparison to the VS-Lite simulations (Figure 7a).

446 Conversely, our results indicate a substantial degree of disturbance at sites in the west of the

447 Highlands, which partially obscures the climate signal and specifically the longer-term trends

448 (Figure 2). 
Differences between the West and Cairngorms disturbance records can be interpreted to

450 reflect the disparity of woodland exploitation. This suggests a greater scale and extent of 451 exploitation in the West from the beginning of the $18^{\text {th }}$ until the mid-19 $9^{\text {th }}$ century, which is also 452 apparent in the RW chronology. The timing of disturbance events occurs systematically in the 453 West Highlands around the mid- $19^{\text {th }}$ century. The presence of inflated RW indices in the West 454 chronology (Figure 6b) around 1850 affects the empirical statistical fit of the detrending curve, 455 biasing the calculation of indices towards the end of the time series (Melvin and Briffa 2008). 456 This results in an underestimation of indices in the latter part of the West chronology which is 457 most apparent in the recent $\sim 40$ year period.

After CID correction, lower mid- $19^{\text {th }}$ century indices in the West chronology translate 459 into higher index values in the late- $20^{\text {th }}$ century, resulting in considerable chronology and 460 climate signal improvement (Figure 6c). The evaluation of West and Cairngorms chronologies 461 before and after CID correction against VS-Lite model simulations supports the instrumental 462 correlation results by validating the general improvement of the climate signal in the post-CID 463 chronologies.

Using two approaches to assess corrected and uncorrected chronologies (Tables 3 and 4), some additional insight can be gained about whether the full length of a post-CID chronology displays improvement or whether any apparent improvement is restricted to the recent period.

467 Based on this information, a more informed decision can be made regarding the suitability of pre-CID or post-CID chronologies for climate reconstruction. In the majority of cases both assessment methods favour the same chronology version. However, in the few instances where

470 there is disagreement, the magnitude of the correlation change of each assessment approach was 471 considered when deciding which version of the chronology should be used for reconstruction 472 development (Rydval 2015). 


\subsection{Disturbance synchronicity}

The synchronicity of detected disturbance events in the Cairngorms and West chronologies (particularly after $\sim 1700$ and even more so after $\sim 1800$ ) may be the result of three possible scenarios; 1) the record of inferred disturbance is exogenous (i.e. $\delta \mathrm{D} 22_{\mathrm{t}}$ in eq.1) and specifically the result of the similar pattern and timing of woodland exploitation that occurred throughout most of the Scottish Highlands as a whole over time; 2) at least some of the disturbance events are related to exogenous causes other than timber clearance which simultaneously affect larger areas or the entire region (for example this may include damage to forests as a result of wind and storms); 3) some of the trends which are being removed are in fact related to climatic variability and their identification and removal from site chronologies throughout the network is reflected in spatially synchronous patterns misinterpreted as disturbance.

The observed synchronous relationship is likely the result of some combination of all three factors. It is not generally possible to definitively attribute a given disturbance event to a specific causal factor with the exception of instances which can be corroborated by documentary evidence. Detailed records do not exist for many locations, but an overview of available historical information clearly identifies forest clearance as the dominant acting force shaping the landscape of the Scottish Highlands over many centuries (e.g. Lindsay 1974; Smout 2003; Smout et al. 2005). While an assessment of the site-specific disturbance histories recorded in historical documentation is unfeasible as part of the analysis presented here, the overall documented patterns of woodland exploitation do offer some general insights.

\subsubsection{Historical context}

The history of woodland exploitation in Scotland is complex and a detailed analysis of the disturbance history is beyond the scope of this study. However, it is important to explore the 

general historical context for the disturbance patterns identified on the sub-regional scale. The lower relative amount of disturbance detected after the mid- $19^{\text {th }}$ century coincides with a general decrease in the overall 'intensity' of wood extraction in the late $19^{\text {th }}$ and $20^{\text {th }}$ century. Although some periods of felling also occurred in the $20^{\text {th }}$ century, in particular during the First and Second World War, such activities were arguably perhaps more localised, less extensive and of a lower magnitude when compared to the scale, extent and duration of exploitation in the 1800s and earlier centuries. Such activities possibly also focussed more on relatively recent plantations not sampled in this study. Furthermore, it is also possible that records of the $20^{\text {th }}$ century events preserved in tree rings may be scarcer due to large scale forest clearance where no seeding trees were left behind in some areas (Smout 1997). It has also been suggested that large surviving trees may become less sensitive to more recent disturbance events as they become the dominant canopy trees (Neil Pederson, pers.comm., 2014).

Large-scale timber extraction in the Highlands was dependent on a combination of factors, primarily determined by the profitability of such efforts and largely driven by demand for wood and the availability and price of foreign timber imports, with accessibility and ease of extraction also playing an important role. For these reasons, periods of more intensive, accelerated exploitation occurred during times of war or other instances of the limited availability / higher cost of timber imports (Oosthoek 2013; Smout et al. 2005; Steven and Carlisle 1959). As a consequence of trade tariffs imposed in relation to the Napoleonic Wars, the beginning of the $19^{\text {th }}$ century saw increased demand for local Scots pine timber which was generally of inferior quality to imported timber of predominantly Scandinavian and Baltic origin (Oosthoek 2013; Smout et al. 2005).

Though not explicitly acknowledged, there are indications that some western locations may have been more heavily exploited at certain times (Smout 1997; Smout et al. 2005). This is supported by suggestions that woodland exploitation in the West Highlands was also generally 
524 less well managed and controlled. Exploitation in general may have also been further

525 exacerbated by land ownership changes after the Jacobite rebellion in 1745 (Callander 1986;

526 Hobbs 2009). Among various ventures, including those of the York Building company which

527 operated in both the Cairngorms and West Highlands, Irish speculators were active in the West

528 Highlands from the 1660s until the late 1730s (especially in the latter part of this period). Their

529 activities included the purchase and indiscriminate exploitation of woodlands including

530 pinewoods which were purchased for timber to be marketed in Ireland where building timber

531 was a scarce resource at the time (Smout et al. 2005). Unsurprisingly, this period of extensive

532 felling coincides with early to mid- $18^{\text {th }}$ century disturbance pulses in the West Highland record

533 (Figure 3).

534

\subsubsection{Wind disturbance and additional factors}

Severe windstorms represent a plausible alternative source of some identified

537 disturbance events. The importance of the limiting effects of wind on growth of Scots pine in

538 the Scottish Highlands has previously been recognised (Moir 2008). There is certainly evidence

539 for the occurrence of severe storms in the past and more recent decades (Dawson 2009), as well

540 as for their damaging effects on stands in the Highlands (Steven and Carlisle 1959). A strong

541 gradient in wind intensity between eastern and (north-)western Scotland (Quine and White

542 1993) would support the greater susceptibility of the West to windier conditions. This increases

543 the possibility of more extensive and severe wind damage occurring at sites in the western and

544 northwest Highlands during severe storm events, which would partially also help to explain the

545 greater disturbance in that sub-region, but also some degree of synchronicity of detected

546 disturbance events in the Highlands as a whole. It is quite possible that anthropogenic woodland

547 exploitation may in fact promote windthrow by weakening remaining stands and increasing

548 exposure to wind by reducing the size and density of forest cover. 
Locally, forest fires or insect outbreaks may also act as an additional source of

550 disturbance (Steven and Carlisle 1959). Regarding the potential removal of common climatic

551 information, individual site pre- and post-CID changes perhaps indicate some degree of over-

552 correction (type-I errors) in those instances where chronologies display weaker agreement with

553 instrumental and synthetic chronology data after CID correction. From a methodological

554 perspective, CID is a relatively new approach for detecting disturbances. As such, the method is

555 undergoing continued development and is evolving in its capability to detect and remove

556 disturbance events. Nevertheless, the considerable improvement of chronologies from the west

557 of Scotland which are known to have experienced extensive episodes of disturbance and also

558 some Cairngorm sites is encouraging and indicates its ability to improve the climate

559 reconstruction potential of RW chronologies affected by disturbance.

\subsection{Average disturbance releases}

The average size of additional growth due to disturbance in each of the sub-regions

563 indicates that in most time periods the average size of disturbance-related growth is the same or

564 similar (apart from the $19^{\text {th }}$ century period when more growth as a result of disturbance is

565 observed in the West). One possible interpretation of this effect is that rather than experiencing

566 a greater degree of disturbance, it is also possible that differential responses to disturbance exist

567 at sites in the two sub-regions. In the periods when additional growth from disturbances is

568 greater in the West, trees in the western sites may be showing a greater response (or greater

569 sensitivity) to disturbance events. This could arguably be related to a differential elevational

570 response by less temperature limited stands to decreased competition, and the greater

571 availability of light and nutrients as neighbouring trees are removed. Other factors could

572 certainly also be involved including differences due to genetic variation in Scots pine

573 throughout Scotland (Forrest 1980), variations in soil type or differences in water balance and 
574 soil moisture between the Cairngorms and parts of western Scotland with considerably wetter

575 conditions in the west of the country (Met Office 2015; Oosthoek 2013).

576 However, this interpretation is unlikely considering that the mean response to

577 disturbance is similar in other periods. Replication does not appear to be a significant factor

578 either since a similar response in the West and Cairngorms chronologies can be observed during

579 periods of high, intermediate and low replication and also when total replication of one of the

580 sub-regional chronologies is higher than for the other.

581 Alternatively, because the largest deviations between the two disturbance chronologies

582 occur during or immediately after those decades when the difference in the relative number of

583 disturbance events between the Cairngorms and the West is greatest, it could be the case that

584 because a larger number of trees are experiencing disturbance-related growth releases at a

585 similar time (i.e. in the early $18^{\text {th }}$ century and to a greater extent around the beginning and

586 middle of the $19^{\text {th }}$ century), this simultaneous (multi-site) cluster of detected disturbances and

587 the subsequent growth release may be the cause of the larger size of expressed mean growth

588 release in those periods. In other words, because the initial growth increase following a

589 disturbance is relatively large, if these releases occur concurrently in many trees, then the mean

590 size of the growth release around that particular time will appear greater than at other times.

591 This would further indicate that the incidence of disturbance events is more synchronous at sites

592 in the West than in the Cairngorms.

\section{Conclusion}

\section{$595 \quad 5.1$ General conclusions}

596 The modern Scottish landscape reflects a long history of human modification of the

597 environment. People have inhabited Scotland for at least 9000 years (Wickham-Jones and 598 Woodman 1998) and have accelerated their influence on the landscape over recent millennia. 
599 During the last millennium, anthropogenic interactions with the landscape have had a 600 particularly profound effect on the pine woodlands of Scotland leading to potential biases 601 affecting tree-ring series with non-climatic disturbance trends. This paper aimed to identify disturbance related growth releases in RW data and 603 minimise the influence of such trends on RW chronologies using the CID method in an attempt 604 to improve the climate signal from those records. CID is a valuable new method for uncovering 605 and reconstructing the ecological and environmental history of forested environments. As 606 demonstrated in this study, using site chronologies from around the Scottish Highlands, it is 607 possible to develop records of the spatial and temporal patterns of disturbance, with applications 608 for the interpretation of woodland history. In addition to identifying the presence of non-climatic disturbance events in the RW 610 record, the CID method is a useful approach for the identification and removal of disturbance 611 influences to "improve" RW series for dendroclimatological purposes. While the CID method 612 should not be considered a panacea for identifying and correcting for disturbance events, it does 613 provide the capability to enhance the climate signal in RW data from sites that have experienced 614 these events in the past. The main conclusions from this study are:

615 - The CID method enhances the climate signal in otherwise noisy RW chronologies 616 affected by disturbance.

617 - Instrumental and VS-Lite model data could only be used to assess chronology 618 performance from 1866 and 1901 onwards, respectively. Evaluation of the full length of 619 individual pre- and post-CID site chronologies was performed by comparison to a 620 Scotland wide MXD composite chronology. The results of chronology comparisons with 621 instrumental temperature data were in overall agreement with VS-Lite based $622 \quad$ assessments. 
- Based on instrumental temperature data and VS-Lite model simulations, the Cairngorms were less systematically disturbed and therefore only limited improvement was observed with the post-CID chronologies. In contrast, the more disturbed West Highland sites showed considerable improvement after correction.

- Greater agreement between the two sub-regional chronologies was observed after CID correction. Identified disturbance patterns were primarily attributed to woodland harvesting and clearance.

\subsection{Future research}

Future research should focus on further development of the CID method, such as the inclusion of alternative detrending curves, additional efficiency optimisation of the disturbance detection and removal mechanisms along with the addition of the detection of growth suppression events. Further development of this method will also explore potential advantages of utilising a multiplicative model of tree growth (Cecile et al. 2013). Application of CID to other types of disturbance events (e.g. pollution, insect or pathogen attacks, storm and wind events), resulting in either prolonged release or suppression signatures, should also be investigated as well as its implementation using a variety of species in a range of environments. Determining whether disturbance events could also be detected in additional tree-ring parameters (such as MXD and stable isotopes) may also be beneficial. If detection in other parameters were possible, then the concurrence (or lack thereof) in these events between parameters could potentially yield additional useful information. Artificial or pseudo-proxy time series could also be used to assess CID performance in more detail, including the likelihood of false detection or failure to detect actual disturbance events. Despite a general attempt to contextualise the identified history of stand disturbance and woodland exploitation within a historical context, this paper provides a new source of information about woodland disturbance 
648

649

650

651

652

653

654

655

656

657

658

659

660

661

662

663

664

665

666

667

668

669

670

671

672

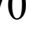

in Scotland that could undoubtedly be exploited further. Future work should therefore focus on developing a more detailed examination and evaluation of the disturbance history together with an assessment of historical records for individual sites (where available) in order to assist with the interpretation of the findings of this study. Such an investigation could for example explore the links between societal and socioeconomic changes and woodland utilisation through time in order to develop a better understanding of past land use and management practices in Scotland. Assessing the role of additional natural factors such as soil moisture and wind on growth, particularly in western Scotland, may also prove useful.

\section{Acknowledgements:}

We wish to thank The Carnegie Trust for the Universities of Scotland for providing funding for Miloš Rydval's PhD. The Scottish pine network expansion has been an ongoing task since 2006 and funding must be acknowledged to the following projects: EU project 'Millennium' (017008-2), Leverhulme Trust project 'RELiC: Reconstructing 8000 years of Environmental and Landscape change in the Cairngorms (F/00 268/BG)' and the NERC project 'SCOT2K: Reconstructing 2000 years of Scottish climate from tree rings (NE/K003097/1)' KJA was also supported by a grant for the US National Science Foundation (ARC-0902051). We also thank Ian Harris for making available the elevation data associated with the CRU TS3.10 temperature dataset, Ed Cook for advice on analysing tree rings for disturbance events, and Rider University for a faculty research fellowship that supported Daniel Druckenbrod. 
673

674

675

676

677

678

679

680

681

682

683

684

685

686

687

688

689

690

691

692

693

694

695

696

697

\section{References:}

Barnard, T.E. 1975. The Maximum Entropy Spectrum and the Burg Technique. Technical Report 1: Advanced Signal Processing. Texas Instruments Incorporated, Dallas, Texas. $\operatorname{ALEX(03)-TR-75-01.~}$

Bebber, D.P., Thomas, S.C., Cole, W.G., and Balsillie, D. 2004. Diameter increment in mature eastern white pine Pinus strobus L. following partial harvest of old-growth stands in Ontario, Canada. Trees, 18(1): 29-34.

Black, B.A., and Abrams, M.D. 2003. Use of boundary-line growth patterns as a basis for dendroecological release criteria. Ecol. Appl. 13(6): 1733-1749.

Black, B.A., and Abrams, M.D. 2004. Development and application of boundary-line release criteria. Dendrochronologia, 22(1): 31-42.

Briffa, K., and Melvin, T. 2011. A Closer Look at Regional Curve Standardization of Tree-Ring Records: Justification of the Need, a Warning of Some Pitfalls, and Suggested Improvements in Its Application. In Dendroclimatology: progress and prospects. Edited by M.K. Hughes, T.W. Swetnam, and H.F. Diaz. Springer, Dordrecht, pp. 113-145.

Čada, V., Svoboda, M., and Janda, P. 2013. Dendrochronological reconstruction of the disturbance history and past development of the mountain Norway spruce in the Bohemian Forest, central Europe. For. Ecol. Manage. 295: 59-68.

Callander, R.F. 1986. The history of native woodlands in the Scottish highlands. In Trees and wildlife in the Scottish uplands. Edited by D. Jenkins. Institute of Terrestrial Ecology, Huntingdon, pp. 40-45.

Cecile, J., Pagnutti, C., and Anand, M. 2013. A likelihood perspective on tree-ring standardization: eliminating modern sample bias. Clim. Past Discuss. 9: 4499-4551.

Cook, E.R. 1985. A Time Series Analysis Approach to Tree Ring Standardization. Ph.D. thesis., University of Arizona, Tucson, Arizona. 
698 Cook, E.R., and Holmes, R.L. 1986. Users manual for program ARSTAN. In Tree-ring 699 chronologies of western North America. Edited by R.L. Holmes, R.K. Adams, and H.C. 700 Fritts. University of Arizona, Tucson, Arizona, pp. 50-65.

701 Cook, E.R., and Kairiukstis, L.A. 1990. Methods of Dendrochronology: applications in the 702 environmental sciences. Kluwer Academic Publishers, Dordrecht, Netherlands.

703 Cook, E.R., and Peters, K. 1981. The smoothing spline: a new approach to standardizing forest interior tree-ring width series for dendroclimatic studies. Tree-Ring Bulletin, 41: 45-53.

Cook, E.R., and Peters, K. 1997. Calculating unbiased tree-ring indices for the study of climatic and environmental change. Holocene, 7(3): 361-370.

Dawson, A.G.D. 2009. So Foul and Fair a Day: A History of Scotland's Weather and Climate. Birlinn, Edinburgh, UK.

Druckenbrod, D.L. 2005. Dendroecological reconstructions of forest disturbance history using time-series analysis with intervention detection. Can. J. For. Res. 35(4): 868-876.

711 Druckenbrod, D.L., Pederson, N., Rentch, J., and Cook, E.R. 2013. A comparison of times 712 series approaches for dendroecological reconstructions of past canopy disturbance events. For. Ecol. Manage. 302: 23-33.

Elling, W., Dittmar, C., Pfaffelmoser, K., and Rötzer, T. 2009. Dendroecological assessment of the complex causes of decline and recovery of the growth of silver fir (Abies alba Mill.)

717 Evans, M.N., Tolwinski-Ward, S.E., Thompson, D.M., and Anchukaitis, K.J. 2013. Applications of proxy system modeling in high resolution paleoclimatology. Quat. Sci.

720 Forrest, G.I. 1980. Genotypic variation among native Scots pine populations in Scotland based on monoterpene analysis. Forestry, 53(2): 101-128. 
722 Foster, D.R. 1988. Disturbance history, community organization and vegetation dynamics of the old-growth Pisgah Forest, south-western New Hampshire, USA. J. Ecol. 76(1): 105-134.

724 Fraver, S., and White, A.S. 2005. Identifying growth releases in dendrochronological studies of 725 forest disturbance. Can. J. For. Res. 35(7): 1648-1656.

Fraver, S., White, A.S., and Seymour, R.S. 2009. Natural disturbance in an old-growth landscape of northern Maine, USA. J. Ecol. 97(2): 289-298.

Gaudio, N., Balandier, P., Perret, S., and Ginisty, C. 2011. Growth of understorey Scots pine 729 (Pinus sylvestris L.) saplings in response to light in mixed temperate forest. Forestry, 84(2): 187-195.

Grissino-Mayer, H.D., and Fritts, H.C. 1997. The International Tree-Ring Data Bank: an enhanced global database serving the global scientific community. Holocene, 7(2): 235238.

Harris, I., Jones, P.D., Osborn, T.J., and Lister, D.H. 2014. Updated high-resolution grids of monthly climatic observations - the CRU TS3.10 Dataset. Int. J. Climatol. 34(3): 623642.

Hobbs, R. 2009. Woodland restoration in Scotland: ecology, history, culture, economics, politics and change. J. Environ. Manage. 90(9): 2857-2865.

Holmes, R.L. 1983. Computer-assisted quality control in tree-ring dating and measurement. Tree-Ring Bulletin, 43: 69-75.

Hughes, M.K., Schweingruber, F.H., Cartwright, D., and Kelly, P.M. 1984. July-August temperature at Edinburgh between 1721 and 1975 from tree-ring density and width data. Nature, 308: 341-344.

Hyvönen, R., Olsson, B.A., Lundkvist, H., and Staaf, H. 2000. Decomposition and nutrient release from Picea abies (L.) Karst. and Pinus sylvestris L. logging residues. For. Ecol. Manage. 126(2): 97-112. 
747 ITRDB - International Tree-Ring Data Bank 2014. National Climatic Data Center [online]. Available from http://www.ncdc.noaa.gov/data-access/paleoclimatologydata/datasets/tree-ring [accessed 20 October 2013].

Jones, P.D., and Lister, D. 2004. The development of monthly temperature series for Scotland and Northern Ireland. Int. J. Climatol. 24(5): 569-590.

Larsson, L. 2014. CooRecorder and Cdendro programs of the CooRecorder / Cdendro package version 7.7 [online]. Available from http://www.cybis.se/forfun/dendro [accessed 03 January 2014].

Lindsay, J.M. 1974. The Use of Woodland in Argyllshire and Perthshire Between 1650 and 1850. Ph.D. thesis, University of Edinburgh, Edinburgh, UK.

Lorimer, C.G., and Frelich, L.E. 1989. A methodology for estimating canopy disturbance 758 frequency and intensity in dense temperate forests. Can. J. For. Res. 19(5): 651-663.

Melvin, T.M., and Briffa, K.R. 2008. A "signal-free" approach to dendroclimatic standardisation. Dendrochronologia, 26(2): 71-86.

761 Met Office 2015. UK Regional Climates [online]. Available from http://www.metoffice.gov.uk/public/weather/climate\#averagesMaps

Nagel, T.A., Levanic, T., and Diaci, J. 2007. A dendroecological reconstruction of disturbance

Moir, A.K. 2008. The dendroclimatology of Modern and Neolithic Scots pine (Pinus sylvestris [accessed 10 April 2015]. in an old-growth Fagus-Abies forest in Slovenia. Ann. For. Sci. 64(8): 891-897.

Nowacki, G.J., and Abrams, M.D. 1997. Radial-growth averaging criteria for reconstructing disturbance histories from presettlement-origin oaks. Ecol. Monogr. 67(2): 225-249.

Oosthoek, J. 2013. Conquering the Highlands: A History of the Afforestation of the Scottish Uplands. Australian National University E-Press, Canberra, Australia. 
772 Osborn, T.J., Briffa, K.R., and Jones, P.D. 1997. Adjusting variance for sample size in tree-ring 773 chronologies and other regional mean timeseries. Dendrochronologia, 15: 89-99.

774 Palviainen, M., Finér, L., Kurka, A.M., Mannerkoski, H., Piirainen, S., and Starr, M. 2004. 775 Decomposition and nutrient release from logging residues after clear-cutting of mixed $776 \quad$ boreal forest. Plant Soil, 263(1): 53-67.

777 Pederson, N., Varner, J.M., and Palik, B.J. 2008. Canopy disturbance and tree recruitment over 778 two centuries in a managed longleaf pine landscape. For. Ecol. Manage. 254(1): 85-95.

779

780

781

782

783

784

785

786

787

788

789

790

791

792

793

794

795

Quine, C.P. and White, I.M.S. 1993. Revised windiness scores for the windthrow hazard classification: The revised scoring method. Forestry Commission Research Information Note No. 230. Forestry Commission, Edinburgh, UK.

Rubino, D.L. and McCarthy, B.C. 2004. Comparative analysis of dendroecological methods used to assess disturbance events. Dendrochronologia, 21(3): 97-115.

Rydval, M. 2015. Dendroclimatic reconstruction of late Holocene summer temperatures in the Scottish Highlands. Ph.D. thesis, University of St Andrews, St Andrews, United Kingdom.

Rydval, M., and Wilson, R. 2012. The impact of industrial SO2 pollution on north Bohemia conifers. Water, Air, Soil Pollut. 223(9): 5727-5744.

Rydval, M., Larsson, L.Å., McGlynn, L., Gunnarson, B.E., Loader, N.J., Young, G.H., and Wilson, R. 2014. Blue Intensity for dendroclimatology: Should we have the blues? Experiments from Scotland. Dendrochronologia, 32(3): 191-204.

Savva, Y., and Berninger, F. 2010. Sulphur deposition causes a large-scale growth decline in boreal forests in Eurasia. Global Biogeochem. Cycles 24(3). doi:10.1029/2009GB003749.

Smout, T.C. 1997. Scottish Woodland History. Scottish Cultural Press, Edinburgh, UK. 
796

797

798

799

800

801

802

803

804

805

806

807

808

809

810

811

812

813

814

815

816

817

818

Smout, T.C. 2003. People and Woods in Scotland: A History. Edinburgh University Press, Edinburgh, UK.

Smout, T.C., MacDonald, A.R., and Watson, F. 2005. A history of the native woodlands of Scotland, 1500-1920. Edinburgh University Press, Edinburgh, UK.

Speer, J.H., Swetnam, T.W., Wickman, B.E., and Youngblood, A. 2001. Changes in pandora moth outbreak dynamics during the past 622 years. Ecology, 82(3): 679-697.

Steven, H.M., and Carlisle, A. 1959. The native pinewoods of Scotland. Oliver and Boyd, Edinburgh, UK.

Stokes, M.A., and Smiley, T.L. 1968. An introduction to tree-ring dating. University of Chicago Press, Chicago, Illinois.

Svoboda, M., Janda, P., Bače, R., Fraver, S., Nagel, T.A., Rejzek, J., Mikoláš, M., Douda, J., Boublík, K., Šamonil, P., Čada, V., Trotsiuk, V., Teodosiu, M., Bouriaud, O., Biriş, A.I., Sýkora, O., Uzel, P., Zelenka, J., Sedlák, V., and Lehejček, J. 2014. Landscape-level variability in historical disturbance in primary Picea abies mountain forests of the Eastern Carpathians, Romania. J. Veg. Sci. 25(2): 386-401.

Swetnam, T.W. 1993. Fire history and climate change in giant sequoia groves. Science 262(5135): 885-889.

Tolwinski-Ward, S.E. 2012. Inference on Tree-ring Width and Paleoclimate Using a Proxy Model of Intermediate Complexity. Ph.D. thesis, University of Arizona, Tucson, Arizona.

Tolwinski-Ward, S.E., Evans, M.N., Hughes, M.K., and Anchukaitis, K.J. 2011. An efficient forward model of the climate controls on interannual variation in tree-ring width. Clim. Dynam. 36(11-12): 2419-2439. 
819 Tolwinski-Ward, S.E., Anchukaitis, K.J., and Evans, M.N. 2013. Bayesian parameter estimation and interpretation for an intermediate model of tree-ring width. Clim. Past 9(4): 14811493.

822

823

824

825

826

827

828

829

830

831

832

833

834

835

836

837

838

839

840

841

Tolwinski-Ward, S.E., Tingley, M.P., Evans, M.N., Hughes, M.K., and Nychka, D.W. 2014. Probabilistic reconstructions of local temperature and soil moisture from tree-ring data with potentially time-varying climatic response. Clim. Dynam. 44(3-4): 791-806.

Vaganov, E.A., Hughes, M.K., and Shashkin, A.V. 2006. Growth Dynamics of Conifer Tree Rings: Images of Past and Future Environments. Springer, Heidelberg, Germany.

Valinger, E., Elfving, B., and Mörling, T. 2000. Twelve-year growth response of Scots pine to thinning and nitrogen fertilisation. For. Ecol. Manage. 134(1): 45-53.

Veblen, T.T., Hadley, K.S., Reid, M.S., and Rebertus, A.J. 1991. The response of subalpine forests to spruce beetle outbreak in Colorado. Ecology 72(1): 213-231.

Veblen, T.T., Hadley, K.S., Nel, E.M., Kitzberger, T., Reid, M., and Villalba, R. 1994. Disturbance regime and disturbance interactions in a Rocky Mountain subalpine forest. J. Ecol. 82(1): 125-135.

Warren, W.G. 1980. On removing the growth trend from dendrochronological data. Tree-ring Bulletin, 40: 35-44.

Wickham-Jones, C.R., and Woodman, P.C. 1998. Studies on the early settlement of Scotland and Ireland. Quatern. Int. 49: 13-20.

Wilson, R., and Elling, W. 2004. Temporal instability in tree-growth/climate response in the Lower Bavarian Forest region: implications for dendroclimatic reconstruction. Trees, 18(1): 19-28.

Yanosky, T.M., and Jarrett, R.D. 2002. Dendrochronologic Evidence for the Frequency and Magnitude of Paleofloods. In Ancient Floods, Modern Hazards. Edited by P.K. House, 
843 R.H. Webb, V.R. Baker and D.R. Levish. American Geophysical Union, Washington $844 \quad$ D.C. 


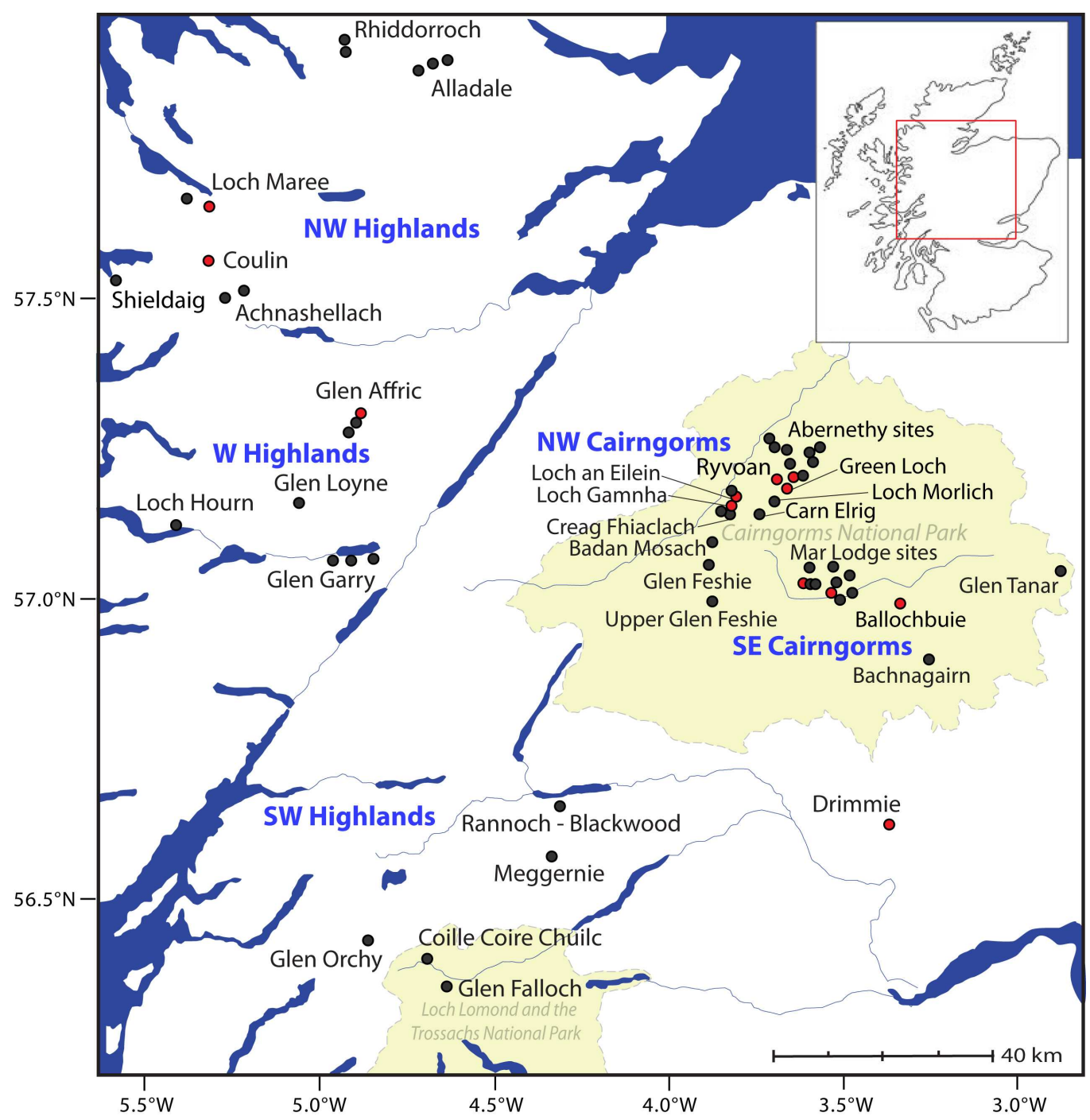

Figure 1: Map of sampled tree ring site network in Scotland (sites marked in red represent sites for which MXD chronologies have been developed in addition to RW). 


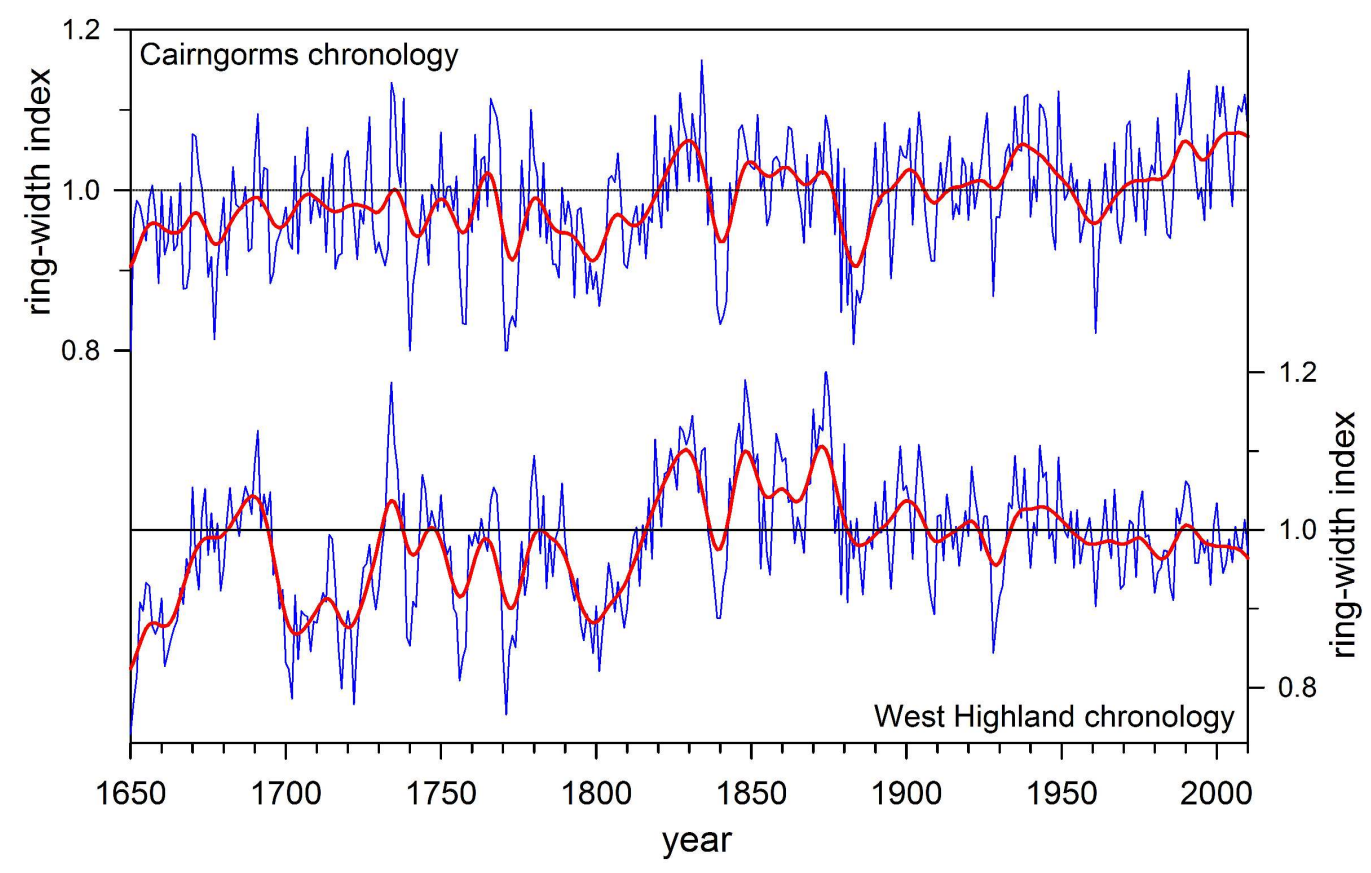

Figure 2: Subregional chronologies from the Cairngorms and West Highlands highlighting trend differences between the two composite chronologies developed using a standard (negative exponential or linear) detrending approach (curves in red represent the original chronologies smoothed with a 20-yr low-pass Gaussian filter to emphasise decadal variability). 

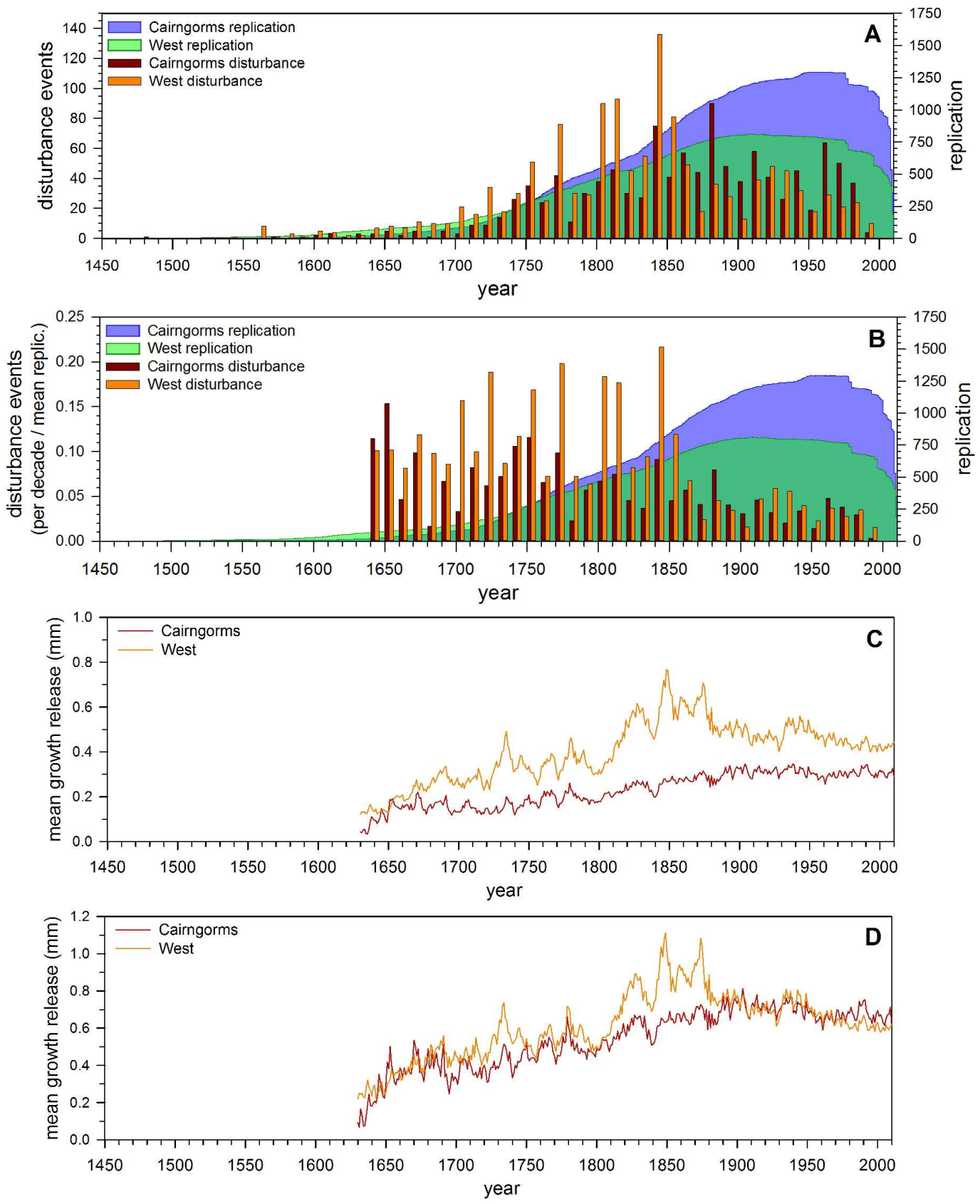

Figure 3: Disturbance event timeline of pulse releases and total replication for the Cairngorms and West Highlands. Disturbance events are grouped according to the decade in which the disturbances were initiated. Results are displayed as (A) the absolute number of events (bars) including replication over time for both subregions (shaded area), and (B) the fraction of disturbed samples as a function mean decadal replication, (C) chronology of the total average amount of growth attributable to disturbance releases and (D) mean size of growth release over time considering only those series which contain disturbance releases at a particular time (results in B, C and D are displayed only for periods when average replication is > 20 for both sub-regional chronologies). 

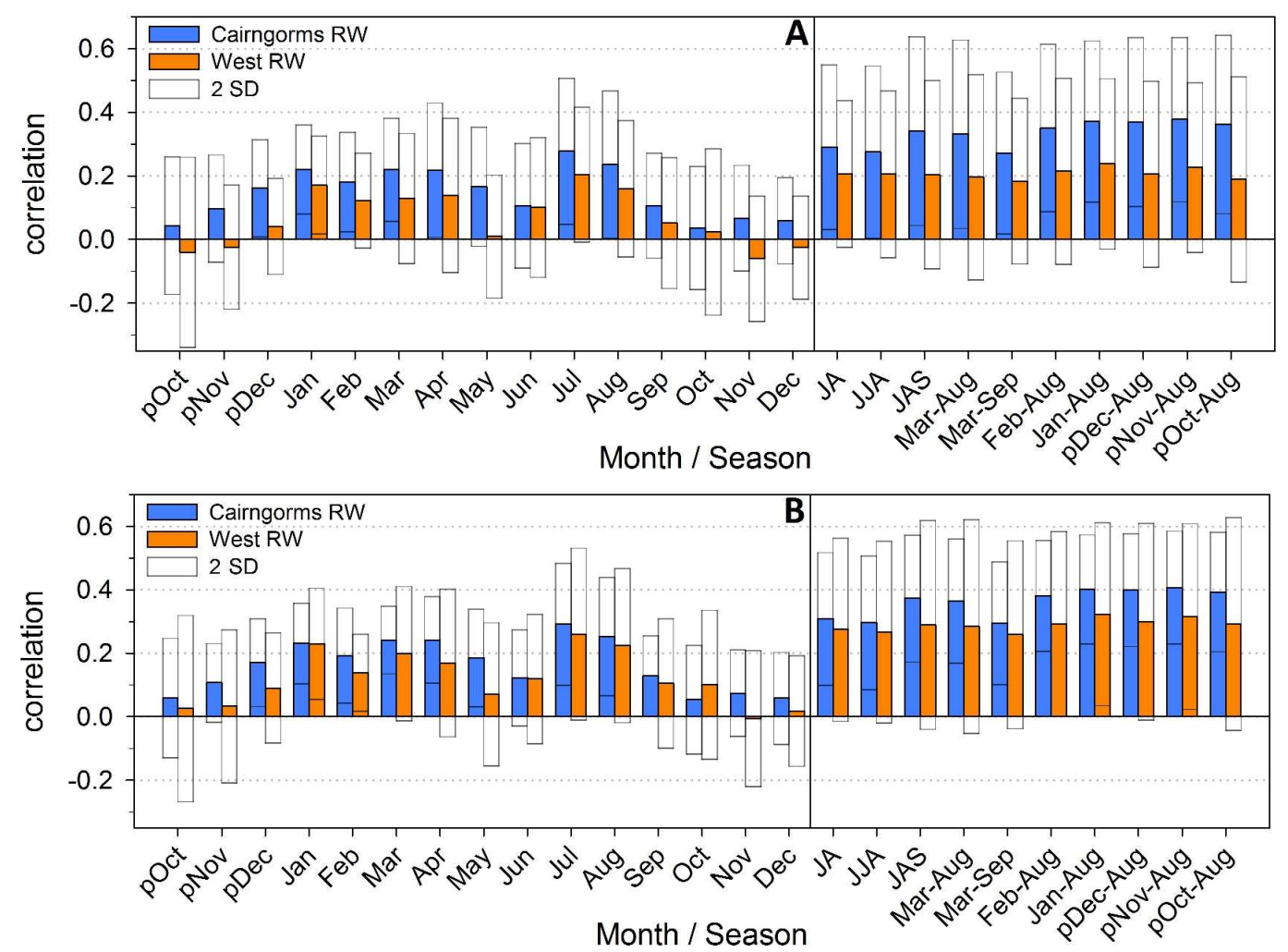

Figure 4: Correlation response functions for Cairngorms and West vs. ESMT temperature using (A) pre-CID and (B) post-CID chronologies with negative exponential or linear detrending. ( 2 standard deviation (SD) range is based on correlations of all individual site chronologies in each sub-region with instrumental temperatures.) 

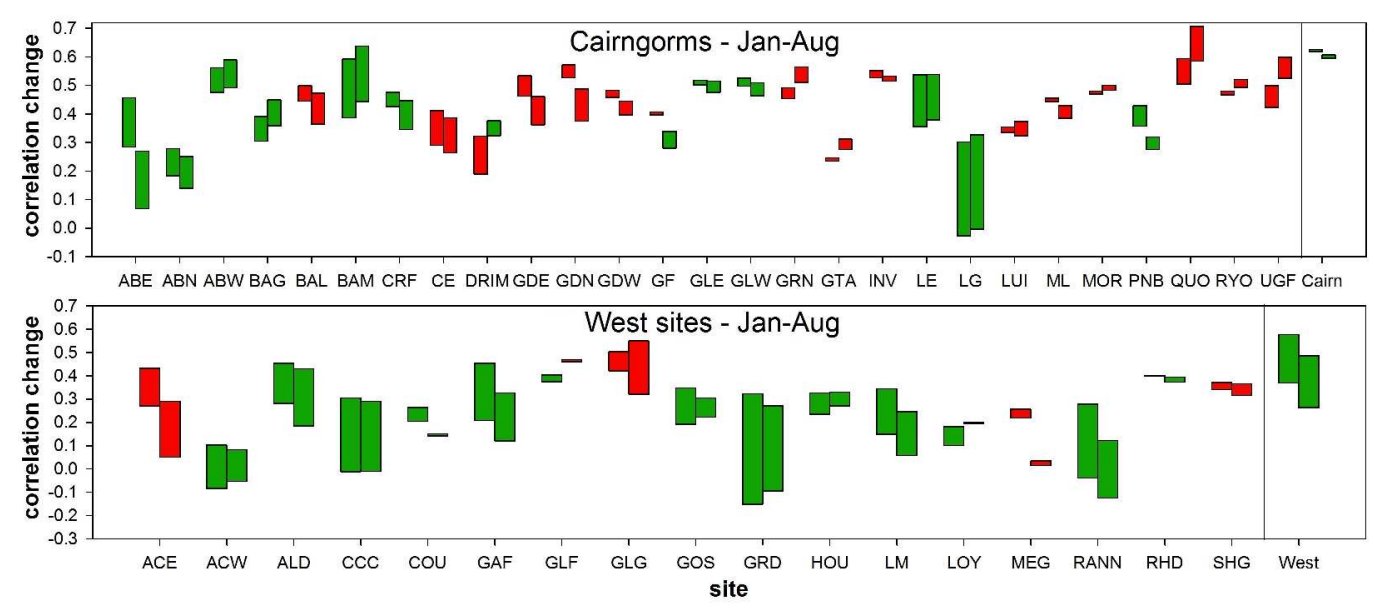

Figure 5: Change in correlation between the pre- and post-CID versions of individual site chronologies with January-August mean seasonal temperature (left bars - using the 1886-2009* period) and with simulated VS-Lite chronologies (right bars - using the 1901-2009* period). Size of green (red) bars indicates magnitude of post-CID correlation increase (decrease) with instrumental or VS-Lite data in relation to preCID versions. Rightmost results represent mean overall change for each sub-region (* chronologies BAG, BAM, CE, GDE, GDW, GLE, GLW, LUI, ML, PNB end in 2008, HOU, LOYNE end in 2007, and GF ends in 2006). 


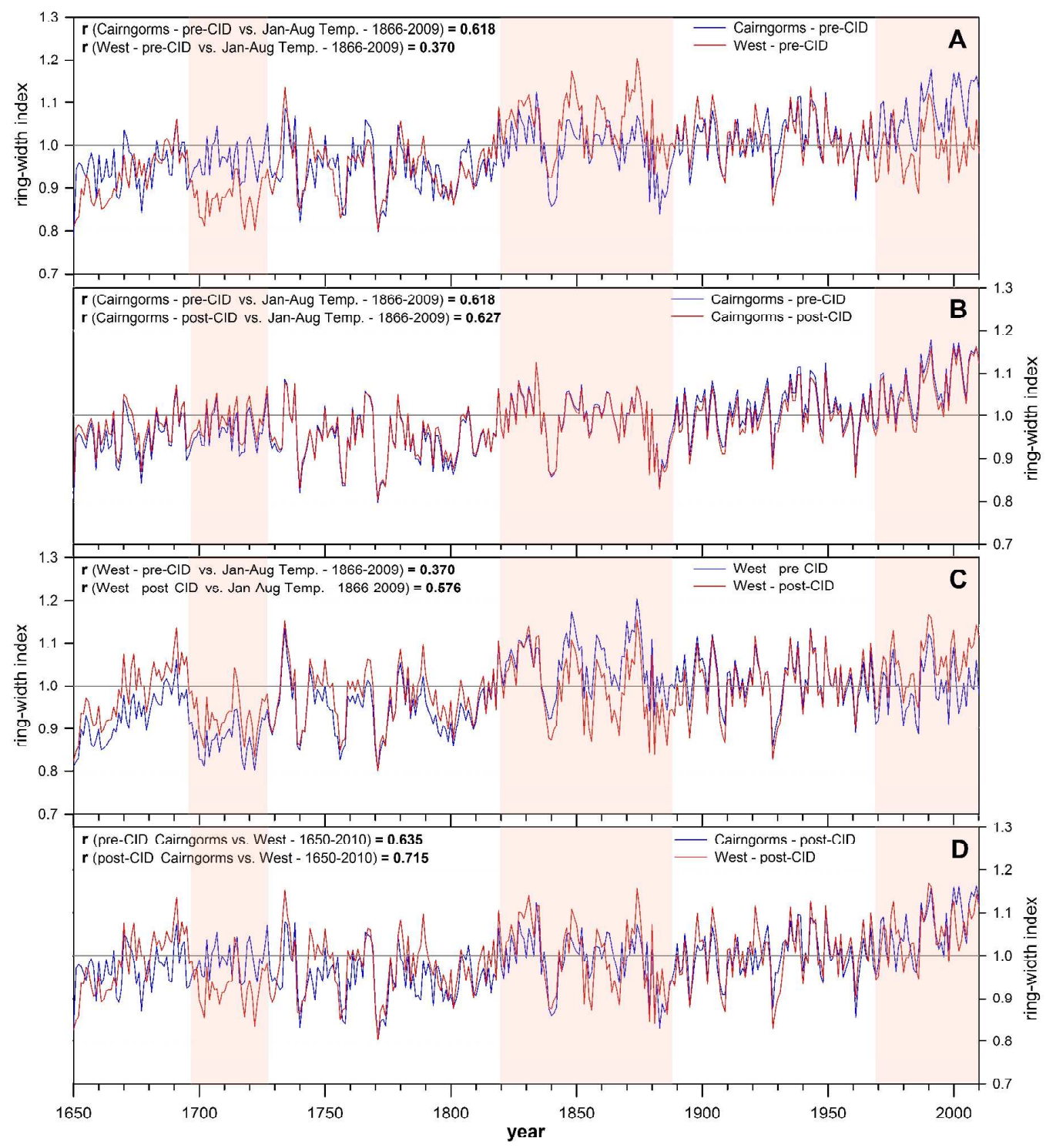

Figure 6: Pre-CID chronologies for (A) the Cairngorms and the West sub-regions, pre- and post-CID chronologies for (B) the Cairngorms and (C) the West, and (D) post-CID chronologies for both sub-regions using SF detrending (notable periods of pre-CID disagreement are highlighted). 


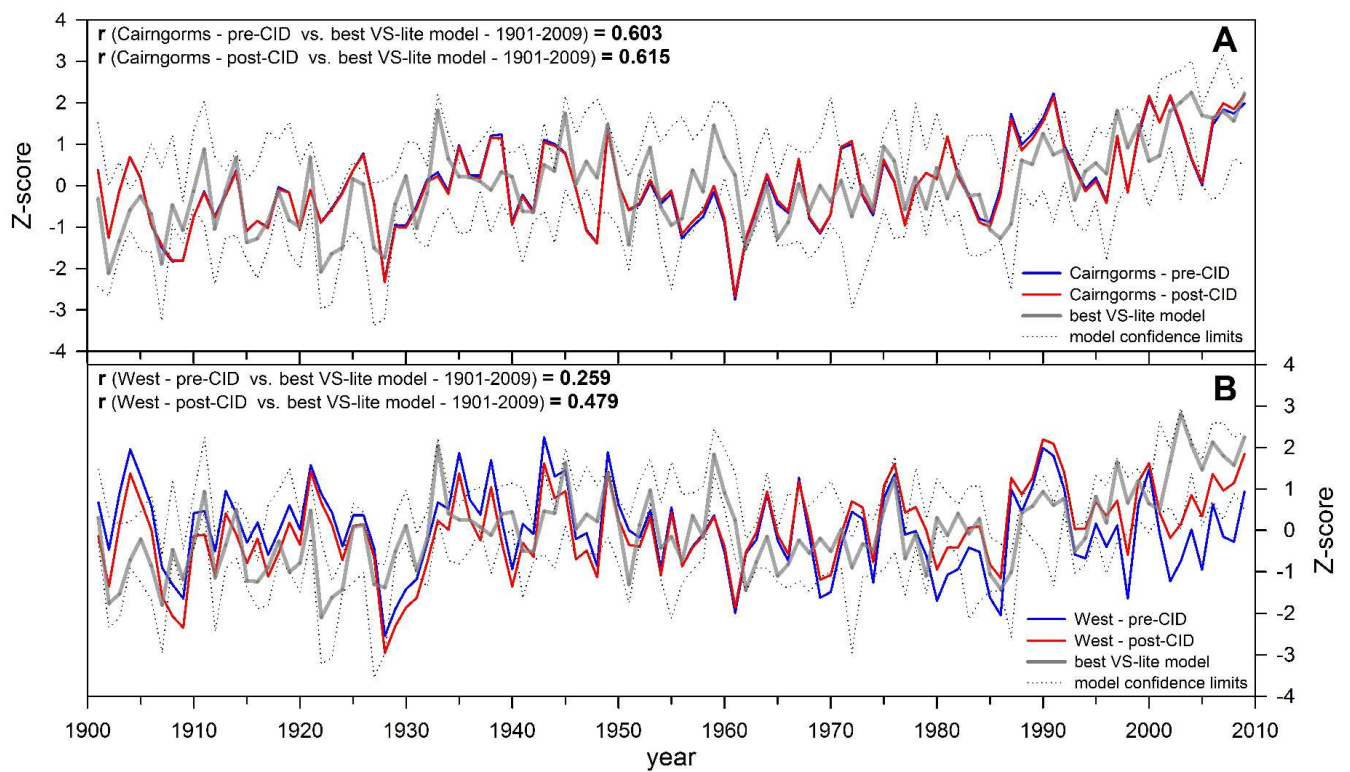

Figure 7: Pre- and post-CID chronologies with SF detrending for (A) the Cairngorms and (B) the West compared against VS-lite models derived using regional grid climate data for the 1901-2009 period (best model based on highest correlation with RW chronology; confidence limits based on min and max ranges from 2500 Monte Carlo simulations). 


\begin{tabular}{|c|c|c|c|c|c|c|c|c|c|}
\hline Region & Site Name & $\begin{array}{l}\text { Site } \\
\text { Code }\end{array}$ & $\begin{array}{l}\begin{array}{c}\text { Latitude } \\
\text { (N) }\end{array} \\
\end{array}$ & $\begin{array}{c}\begin{array}{c}\text { Longitude } \\
\text { (W) }\end{array} \\
\end{array}$ & $\begin{array}{l}\text { Elevation } \\
\text { (m.a.s.I.) }\end{array}$ & $\begin{array}{l}\text { First } \\
\text { Year } \\
\end{array}$ & $\begin{array}{l}\text { Last } \\
\text { Year }\end{array}$ & $\begin{array}{l}\text { No. of } \\
\text { series }\end{array}$ & $\begin{array}{c}\text { Period covered } \\
\text { by } \geq 10 \text { series }\end{array}$ \\
\hline \multirow[t]{2}{*}{ North Highlands } & Alladale & ALD/UAL & $57^{\circ} 52^{\prime}$ & $4^{\circ} 42^{\prime}$ & $280-380$ & 1626 & 2012 & 52 & 1743-2012 \\
\hline & Rhidorroch & RHD & $57^{\circ} 53^{\prime}$ & $4^{\circ} 59^{\prime}$ & $180-230$ & 1708 & 2012 & 24 & $1762-2012$ \\
\hline \multirow[t]{8}{*}{ NW Highlands } & Achnashellach-East & ACE & $57^{\circ} 29^{\prime}$ & $5^{\circ} 15^{\prime}$ & $100-130$ & 1711 & 2009 & 28 & 1750-2009 \\
\hline & Achnashellach-West & ACW & $57^{\circ} 28^{\prime}$ & $5^{\circ} 18^{\prime}$ & $100-120$ & 1767 & 2009 & 21 & $1865-2009$ \\
\hline & $\underline{\text { Coulin }}$ & $\underline{\mathrm{COU}}$ & $\underline{57^{\circ} 32^{\prime}}$ & $\underline{5^{\circ} 21^{\prime}}$ & $\underline{250}$ & $\underline{1636}$ & $\underline{2009}$ & $\underline{67}$ & $\underline{1702-2009}$ \\
\hline & Coulin (MXD) & $\underline{\mathrm{COU}}$ & $\underline{57^{\circ} 32^{\prime}}$ & $\underline{5^{\circ} 21^{\prime}}$ & $\underline{250}$ & $\underline{1671}$ & $\underline{1978}$ & $\underline{21}$ & $\underline{1793-1978}$ \\
\hline & Glen Grudie & GRD & $57^{\circ} 38^{\prime}$ & $5^{\circ} 25^{\prime}$ & $70-120$ & 1634 & 2009 & 30 & $1728-2009$ \\
\hline & Loch Maree & $\underline{\mathrm{LM}}$ & $\underline{57^{\circ} 37^{\prime}}$ & $\underline{5^{\circ} 21^{\prime}}$ & $\underline{100}$ & $\underline{1621}$ & $\underline{2009}$ & $\underline{70}$ & $\underline{1748-2009}$ \\
\hline & $\underline{\text { Loch Maree (MXD) }}$ & $\underline{\mathrm{LM}}$ & $\underline{57^{\circ} 37^{\prime}}$ & $\underline{5^{\circ} 21^{\prime}}$ & $\underline{100}$ & $\underline{1756}$ & $\underline{1978}$ & $\underline{16}$ & $\underline{1846-1978}$ \\
\hline & Shieldaig & SHG & $57^{\circ} 30^{\prime}$ & $5^{\circ} 37^{\prime}$ & $10-100$ & 1801 & 2011 & 45 & 1866-2011 \\
\hline \multirow[t]{5}{*}{ West Highlands } & Glen Affric & $\underline{\text { GAF }}$ & $\underline{57^{\circ} 17^{\prime}}$ & $\underline{4^{\circ} 55^{\prime}}$ & $\underline{300}$ & $\underline{1693}$ & $\underline{2013}$ & $\underline{189}$ & $\underline{1713-2013}$ \\
\hline & Glen Affric (MXD) & GAF & $\underline{57^{\circ} 17^{\prime}}$ & $4^{\circ} 55^{\prime}$ & $\underline{300}$ & 1728 & 2013 & $\underline{50}$ & $1758-2013$ \\
\hline & Glen Garry & GLG & $57^{\circ} 03^{\prime}$ & $4^{\circ} 56^{\prime}$ & 190 & 1747 & 2009 & 41 & 1799-2009 \\
\hline & Loch Hourn & $\mathrm{HOU}$ & $57^{\circ} 07^{\prime}$ & $5^{\circ} 27^{\prime}$ & $90-240$ & 1802 & 2007 & 10 & 1859-2007 \\
\hline & Glen Loyne & LOY & $57^{\circ} 09^{\prime}$ & $5^{\circ} 05^{\prime}$ & $240-370$ & 1458 & 2007 & 57 & 1559-2003 \\
\hline \multirow[t]{5}{*}{ SW Highlands } & Coille Coire Chuilc & $\mathrm{ccc}$ & $56^{\circ} 25^{\prime}$ & $4^{\circ} 42^{\prime}$ & $210-280$ & 1686 & 2011 & 20 & $1828-2011$ \\
\hline & Glen Falloch & GLF & $56^{\circ} 22^{\prime}$ & $4^{\circ} 39^{\prime}$ & $160-200$ & 1508 & 2011 & 98 & $1600-2011$ \\
\hline & Glen Orchy & Gos & $56^{\circ} 27^{\prime}$ & $4^{\circ} 53^{\prime}$ & $200-210$ & 1710 & 2009 & 22 & 1833-2009 \\
\hline & Meggernie & MEG & $56^{\circ} 34^{\prime}$ & $4^{\circ} 20^{\prime}$ & 325 & 1742 & 2011 & 20 & $1854-2011$ \\
\hline & Rannoch & RANN & $56^{\circ} 40^{\prime}$ & $4^{\circ} 19^{\prime}$ & 320 & 1703 & 2010 & 81 & $1784-2010$ \\
\hline \multirow[t]{10}{*}{ NW Cairngorms } & Abernethy - East & ABE & $57^{\circ} 13^{\prime}$ & $3^{\circ} 34^{\prime}$ & $340-450$ & 1634 & 2009 & 68 & $1747-2009$ \\
\hline & Abernethy - North & ABN & $57^{\circ} 14^{\prime}$ & $3^{\circ} 41^{\prime}$ & $240-340$ & 1859 & 2009 & 84 & $1863-2009$ \\
\hline & Abernethy - West & ABW & $57^{\circ} 12^{\prime}$ & $3^{\circ} 38^{\prime}$ & $350-420$ & 1735 & 2009 & 80 & 1783-2009 \\
\hline & Abernethy - West (MXD) & ABW & $57^{\circ} 12^{\prime}$ & $3^{\circ} 38^{\prime}$ & $350-420$ & 1691 & 2013 & 13 & $1864-2013$ \\
\hline & Badan Mosach & BAM & $57^{\circ} 03^{\prime}$ & $3^{\circ} 53^{\prime}$ & $370-420$ & 1763 & 2008 & 25 & $1845-2008$ \\
\hline & Creag Fhiaclach & CRF & $57^{\circ} 08^{\prime}$ & $3^{\circ} 49^{\prime}$ & $500-550$ & 1690 & 2009 & 61 & $1769-2009$ \\
\hline & Carn Eilrig & CRNE & $57^{\circ} 08^{\prime}$ & $3^{\circ} 46^{\prime}$ & $480-540$ & 1735 & 2008 & 23 & $1824-2008$ \\
\hline & Glen Feshie & GF & $57^{\circ} 05^{\prime}$ & $3^{\circ} 52^{\prime}$ & $480-540$ & 1811 & 2006 & 24 & $1849-2006$ \\
\hline & Green Loch & GRN & $57^{\circ} 10^{\prime}$ & $3^{\circ} 39^{\prime}$ & $370-480$ & 1607 & 2013 & 141 & $1721-2013$ \\
\hline & Green Loch (MXD) & GRN & $57^{\circ} 10^{\prime}$ & $3^{\circ} 39^{\prime}$ & $370-480$ & 1734 & 2013 & 10 & 1876-1909 \\
\hline
\end{tabular}

Table 1: Summary information for sites and site chronologies from the Scottish Highlands. (Chronologies which include data archived in the ITRDB are underscored.) 
Table 1 (continued)

\begin{tabular}{|c|c|c|c|c|c|c|c|c|c|}
\hline Region & Site Name & $\begin{array}{c}\text { Site } \\
\text { Code }\end{array}$ & $\begin{array}{l}\text { Latitude } \\
\text { (N) }\end{array}$ & $\begin{array}{c}\begin{array}{c}\text { Longitude } \\
\text { (W) }\end{array} \\
\end{array}$ & $\begin{array}{c}\begin{array}{c}\text { Elevation } \\
\text { (m.a.s.I.) }\end{array} \\
\end{array}$ & $\begin{array}{l}\text { First } \\
\text { Year }\end{array}$ & $\begin{array}{l}\text { Last } \\
\text { Year }\end{array}$ & $\begin{array}{l}\text { No. of } \\
\text { series }\end{array}$ & $\begin{array}{c}\text { Period covered } \\
\text { by } \geq 10 \text { series }\end{array}$ \\
\hline \multirow[t]{8}{*}{ NW Cairngorms } & Loch an Eilein & LE & $57^{\circ} 09^{\prime}$ & $3^{\circ} 49^{\prime}$ & 260 & 1755 & 2013 & 173 & $1841-2013$ \\
\hline & Loch an Eilein (MXD) & LE & $57^{\circ} 09^{\prime}$ & $3^{\circ} 49^{\prime}$ & 260 & 1828 & 2013 & 18 & $1871-2013$ \\
\hline & Loch Gamnha & LG & $57^{\circ} 08^{\prime}$ & $3^{\circ} 50^{\prime}$ & 275 & 1694 & 2010 & 36 & $1775-2010$ \\
\hline & Loch Gamnha (MXD) & LG & $57^{\circ} 08^{\prime}$ & $3^{\circ} 50^{\prime}$ & 275 & 1763 & 2013 & 20 & $1851-2013$ \\
\hline & Morlich & MOR & $57^{\circ} 09^{\prime}$ & $3^{\circ} 41^{\prime}$ & $410-450$ & 1740 & 2009 & 26 & $1782-2006$ \\
\hline & Ryvoan & RYO & $57^{\circ} 10^{\prime}$ & $3^{\circ} 39^{\prime}$ & $420-480$ & 1778 & 2011 & 25 & 1794-2011 \\
\hline & Ryvoan (MXD) & RYO & $57^{\circ} 10^{\prime}$ & $3^{\circ} 39^{\prime}$ & $420-480$ & 1769 & 2011 & 17 & $1828-2011$ \\
\hline & Upper Glen Feshie & UGF & $56^{\circ} 59^{\prime}$ & $3^{\circ} 52^{\prime}$ & $400-520$ & 1718 & 2010 & 90 & $1754-2010$ \\
\hline \multirow[t]{13}{*}{ SE Cairngorms } & Derry East & $\mathrm{GDE}$ & $\underline{57^{\circ} 01^{\prime}}$ & $\underline{3^{\circ} 34^{\prime}}$ & $480-530$ & 1629 & $\underline{2008}$ & $\underline{54}$ & $1741-2008$ \\
\hline & Derry East (MXD) & $\underline{G D E}$ & $\underline{57^{\circ} 01^{\prime}}$ & $\underline{3^{\circ} 34^{\prime}}$ & $\underline{480-530}$ & $\underline{1773}$ & $\underline{1978}$ & $\underline{26}$ & $\underline{1806-1978}$ \\
\hline & Derry North & GDN & $57^{\circ} 03^{\prime}$ & $3^{\circ} 35^{\prime}$ & $530-600$ & 1477 & 2010 & 71 & $1617-2010$ \\
\hline & Derry West & GDW & $57^{\circ} 01^{\prime}$ & $3^{\circ} 35^{\prime}$ & $450-520$ & 1739 & 2008 & 18 & $1773-2008$ \\
\hline & GhleannEast & GLE & $57^{\circ} 02^{\prime}$ & $3^{\circ} 28^{\prime}$ & $490-540$ & 1697 & 2008 & 31 & $1760-2008$ \\
\hline & GhleannWest & GLW & $57^{\circ} 03^{\prime}$ & $3^{\circ} 31^{\prime}$ & $480-550$ & 1744 & 2008 & 24 & $1764-2008$ \\
\hline & Glen Tanar & GTA & $57^{\circ} 01^{\prime}$ & $2^{\circ} 50^{\prime}$ & $306-379$ & 1699 & 2012 & 25 & $1822-2012$ \\
\hline & $\underline{\text { Inverey }}$ & $\underline{\text { INV }}$ & $\underline{57^{\circ} 00^{\prime}}$ & $\underline{3^{\circ} 31^{\prime}}$ & $\underline{500-550}$ & $\underline{1706}$ & $\underline{2011}$ & $\underline{55}$ & $\underline{1720-2011}$ \\
\hline & Inverey (MXD) & $\underline{I N V}$ & $\underline{57^{\circ} 00^{\prime}}$ & $\underline{3^{\circ} 31^{\prime}}$ & $\underline{500-550}$ & 1706 & 1976 & $\underline{24}$ & $\underline{1731-1976}$ \\
\hline & Luibeg & LUI & $57^{\circ} 01^{\prime}$ & $3^{\circ} 36^{\prime}$ & $460-540$ & 1657 & 2008 & 31 & $1711-2008$ \\
\hline & Mar Lodge & MAL & $56^{\circ} 59^{\prime}$ & $3^{\circ} 30^{\prime}$ & 350 & 1828 & 2008 & 26 & $1837-2008$ \\
\hline & Upper Punch Bowl & PNB & $57^{\circ} 00^{\prime}$ & $3^{\circ} 28^{\prime}$ & $450-550$ & 1681 & 2008 & 22 & 1839-2008 \\
\hline & Quoich & QUO & $57^{\circ} 01^{\prime}$ & $3^{\circ} 31^{\prime}$ & $430-500$ & 1657 & 2011 & 43 & $1707-2011$ \\
\hline \multirow[t]{5}{*}{ South Cairngorms } & Bachnagairn & BAG & $56^{\circ} 54^{\prime}$ & $3^{\circ} 14^{\prime}$ & $500-560$ & 1833 & 2008 & 20 & $1847-2008$ \\
\hline & Ballochbuie & BAL & $\underline{56^{\circ} 58^{\prime}}$ & $\underline{3^{\circ} 19^{\prime}}$ & $\underline{300-500}$ & $\underline{1589}$ & $\underline{2011}$ & $\underline{86}$ & $\underline{1677-2011}$ \\
\hline & Ballochbuie (MXD) & BAL & $\underline{56^{\circ} 58^{\prime}}$ & $\underline{3^{\circ} 19^{\prime}}$ & $\underline{300-500}$ & $\underline{1675}$ & $\underline{2011}$ & $\underline{44}$ & $\underline{1729-2011}$ \\
\hline & Drimmie & $\underline{D R I M}$ & $\underline{56^{\circ} 38^{\prime}}$ & $\underline{3^{\circ} 21^{\prime}}$ & $\underline{215}$ & 1824 & $\underline{2010}$ & $\underline{38}$ & $\underline{1832-2010}$ \\
\hline & Drimmie (MXD) & $\underline{D R I M}$ & $\underline{56^{\circ} 38^{\prime}}$ & $\underline{3^{\circ} 21^{\prime}}$ & $\underline{215}$ & 1828 & 1976 & $\underline{22}$ & $\underline{1843-1976}$ \\
\hline
\end{tabular}




\begin{tabular}{lll}
\hline Temperature response parameters & & \\
\hline Threshold temperature for $g_{T}>0$ & $T_{1}$ & $\in\left[0^{\circ} \mathrm{C}, 8.5^{\circ} \mathrm{C}\right]$ \\
Threshold temperature for $g_{T}=1$ & $T_{2}$ & $\in\left[9^{\circ} \mathrm{C}, 20^{\circ} \mathrm{C}\right]$ \\
& & \\
\hline Moisture response parameters & & \\
\hline Threshold soil moisture for $g_{M}>0$ & $M_{1}$ & $\in[0.01,0.03] \mathrm{v} / \mathrm{v}$ \\
Threshold soil moisture for $g_{M}=1$ & $M_{2}$ & $\in[0.1,0.5] \mathrm{v} / \mathrm{v}$ \\
& & \\
\hline Soil moisture parameters & & \\
\hline Runoff parameter 1 & $\alpha$ & $0.093 \mathrm{month}^{-1}$ \\
Runoff parameter 2 & $\mu$ & 5.8 \\
Runoff parameter 3 & $m$ & 4.886 \\
Max. moisture held by soil & $\mathrm{W}_{\max }$ & $0.76 \mathrm{v} / \mathrm{v}$ \\
Min. moisture held by soil & $\mathrm{W}_{\min }$ & $0.01 \mathrm{v} / \mathrm{v}$ \\
Root (bucket) depth & $d_{r}$ & $1000 \mathrm{~mm}$ \\
& & \\
\hline Integration window parameters & & \\
\hline Integration start month & $\mathrm{I}_{0}$ & $-2(\mathrm{pNov})$ \\
Integration end month & $\mathrm{I}_{f}$ & $12(\mathrm{Dec})$ \\
\hline
\end{tabular}

Table 2: VS-lite model parameters. $g_{T}$ and $g_{M}$ represents growth response function due to temperature and moisture, respectively - (adapted from Table 1 in Tolwinsi-Ward et al. (2011)). 


\begin{tabular}{|c|c|c|c|c|c|c|c|}
\hline & $\begin{array}{c}\text { Jan-Aug } \\
\text { temp. }\end{array}$ & MXD & Agreement? & & $\begin{array}{c}\text { Jan-Aug } \\
\text { temp. }\end{array}$ & MXD & Agreement? \\
\hline ABE-pre-CID & 0.285 & 0.404 & & GLW-pre-CID & 0.498 & 0.420 & \\
\hline ABE-post-CID & 0.457 & 0.375 & & GLW-post-CID & 0.526 & 0.371 & \\
\hline ABN-pre-CID & 0.183 & 0.301 & & GRN-pre-CID & 0.492 & 0.454 & \\
\hline ABN-post-CID & 0.279 & 0.370 & & GRN-post-CID & 0.453 & 0.456 & \\
\hline ABW-pre-CID & 0.476 & 0.520 & & GTA-pre-CID & 0.247 & 0.345 & \\
\hline ABW-post-CID & 0.562 & 0.502 & & GTA-post-CID & 0.235 & 0.324 & \\
\hline BAG-pre-CID & 0.304 & 0.335 & & INV-pre-CID & 0.552 & 0.570 & \\
\hline BAG-post-CID & 0.392 & 0.397 & & INV-post-CID & 0.528 & 0.552 & \\
\hline BAL-pre-CID & 0.499 & 0.517 & & LE-pre-CID & 0.356 & 0.368 & \\
\hline BAL-post-CID & 0.445 & 0.405 & & LE-post-CID & 0.537 & 0.486 & \\
\hline BAM-pre-CID & 0.387 & 0.372 & & LG-pre-CID & -0.027 & 0.195 & \\
\hline BAM-post-CID & 0.592 & 0.540 & & LG-post-CID & 0.302 & 0.272 & \\
\hline CRF-pre-CID & 0.426 & 0.416 & & LUI-pre-CID & 0.355 & 0.351 & \\
\hline CRF-post-CID & 0.475 & 0.396 & & LUI-post-CID & 0.336 & 0.368 & \\
\hline CRNE-pre-CID & 0.412 & 0.333 & & ML-pre-CID & 0.456 & 0.352 & \\
\hline CRNE-post-CID & 0.291 & 0.264 & & ML-post-CID & 0.444 & 0.353 & \\
\hline DRIM-pre-CID & 0.323 & 0.241 & & MOR-pre-CID & 0.480 & 0.468 & \\
\hline DRIM-post-CID & 0.190 & 0.009 & & MOR-post-CID & 0.470 & 0.461 & \\
\hline GDE-pre-CID & 0.534 & 0.578 & & PNB-pre-CID & 0.358 & 0.293 & \\
\hline GDE-post-CID & 0.463 & 0.524 & & PNB-post-CID & 0.429 & 0.344 & \\
\hline GDN-pre-CID & 0.572 & 0.586 & & QUO-pre-CID & 0.594 & 0.485 & \\
\hline GDN-post-CID & 0.527 & 0.483 & & QUO-post-CID & 0.504 & 0.414 & \\
\hline GDW-pre-CID & 0.483 & 0.440 & & RYO-pre-CID & 0.480 & 0.470 & \\
\hline GDW-post-CID & 0.458 & 0.420 & & RYO-post-CID & 0.467 & 0.447 & \\
\hline GF-pre-CID & 0.407 & 0.400 & & UGF-pre-CID & 0.499 & 0.501 & \\
\hline GF-post-CID & 0.397 & 0.405 & & UGF-post-CID & 0.424 & 0.379 & \\
\hline GLE-pre-CID & 0.502 & 0.480 & & & & & \\
\hline GLE-post-CID & 0.519 & 0.407 & & & & & \\
\hline
\end{tabular}

Table 3: Correlation results of individual Cairngorms site pre-CID and post-CID (SF) chronologies with instrumental temperature and the Scotland MXD chronology (SF detrending). Numbers in green indicate post-CID correlation increase, red $=$ correlation decrease, green $=$ correlation increase, blue $=$ minimal correlation change $(\leq 0.01)$. The last column summarises whether the direction of change (increase or decrease) in correlation with instrumental temperature is in agreement (green) or disagreement (red) with the change in correlation with the Scotland MXD chronology (note that for each site where there is no considerable correlation change (marked as blue) in at least one of the indicators, this is not considered to constitute disagreement regardless of the direction of change in the second indicator). 


\begin{tabular}{|c|c|c|c|c|c|c|c|}
\hline & $\begin{array}{c}\text { Jan-Aug } \\
\text { temp. }\end{array}$ & MXD & Agreement? & & $\begin{array}{c}\text { Jan-Aug } \\
\text { temp. }\end{array}$ & MXD & Agreement? \\
\hline ACE-pre-CID & 0.431 & 0.456 & & GRD-pre-CID & -0.152 & -0.035 & \\
\hline ACE-post-CID & 0.271 & 0.338 & & GRD-post-CID & 0.323 & 0.326 & \\
\hline ACW-pre-CID & -0.084 & 0.062 & & HOU-pre-CID & 0.234 & 0.225 & \\
\hline ACW-post-CID & 0.103 & 0.224 & & HOU-post-CID & 0.326 & 0.327 & \\
\hline ALD-pre-CID & 0.283 & 0.480 & & LM-pre-CID & 0.149 & 0.223 & \\
\hline ALD-post-CID & 0.453 & 0.472 & & LM-post-CID & 0.344 & 0.440 & \\
\hline CCC-pre-CID & -0.011 & 0.116 & & LOY-pre-CID & 0.100 & 0.298 & \\
\hline CCC-post-CID & 0.305 & 0.320 & & LOY-post-CID & 0.182 & 0.384 & \\
\hline COU-pre-CID & 0.205 & 0.360 & & MEG-pre-CID & 0.256 & 0.261 & \\
\hline COU-post-CID & 0.265 & 0.313 & & MEG-post-CID & 0.218 & 0.231 & \\
\hline GAF-pre-CID & 0.208 & 0.470 & & RANN-pre-CID & -0.038 & 0.127 & \\
\hline GAF-post-CID & 0.453 & 0.564 & & RANN-post-CID & 0.278 & 0.362 & \\
\hline GLF-pre-CID & 0.374 & 0.282 & & RHD-pre-CID & 0.401 & 0.405 & \\
\hline GLF-post-CID & 0.403 & 0.248 & & RHD-post-CID & 0.398 & 0.387 & \\
\hline GLG-pre-CID & 0.503 & 0.498 & & SHG-pre-CID & 0.371 & 0.338 & \\
\hline GLG-post-CID & 0.422 & 0.441 & & SHG-post-CID & 0.341 & 0.273 & \\
\hline GOS-pre-CID & 0.193 & 0.008 & & & & & \\
\hline GOS-post-CID & 0.348 & 0.241 & & & & & \\
\hline
\end{tabular}

Table 4: Correlation results of individual West site pre-CID and post-CID (SF) chronologies with instrumental temperature and the Scotland MXD chronology (SF detrending). Numbers in green indicate post-CID correlation increase, red $=$ correlation decrease, green $=$ correlation increase, blue $=$ no considerable correlation change $(\leq$ $0.01)$. The last column summarises whether the direction of change (increase or decrease) in correlation with instrumental temperature is in agreement (green) or disagreement (red) with the change in correlation with the Scotland MXD chronology (note that for each site where there is no considerable correlation change (marked as blue) in at least one of the indicators, this is not considered to constitute disagreement regardless of the direction of change in the second indicator). 
Chronologies before and after CID correction and disturbance chronologies for the Cairngorms sites:
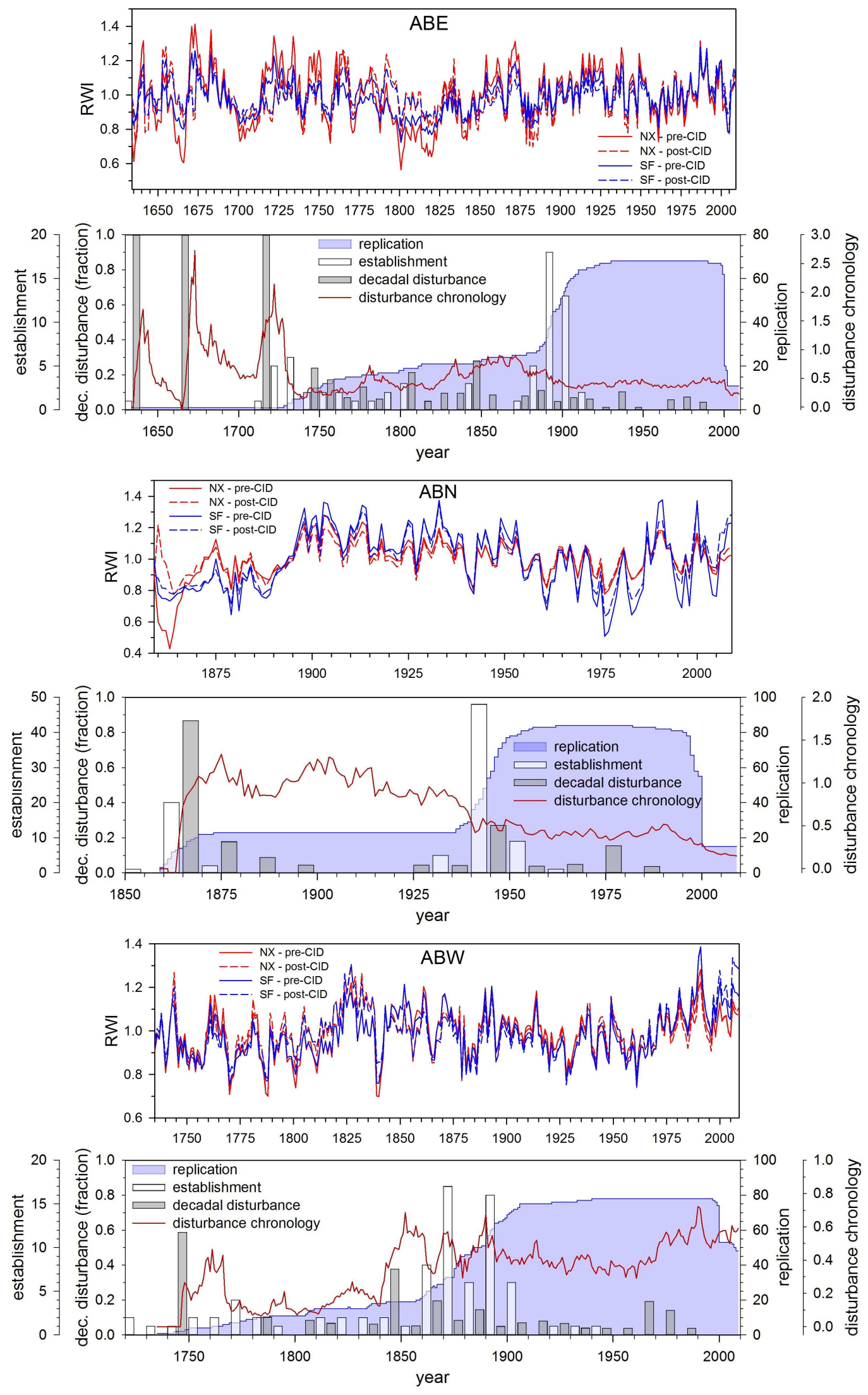

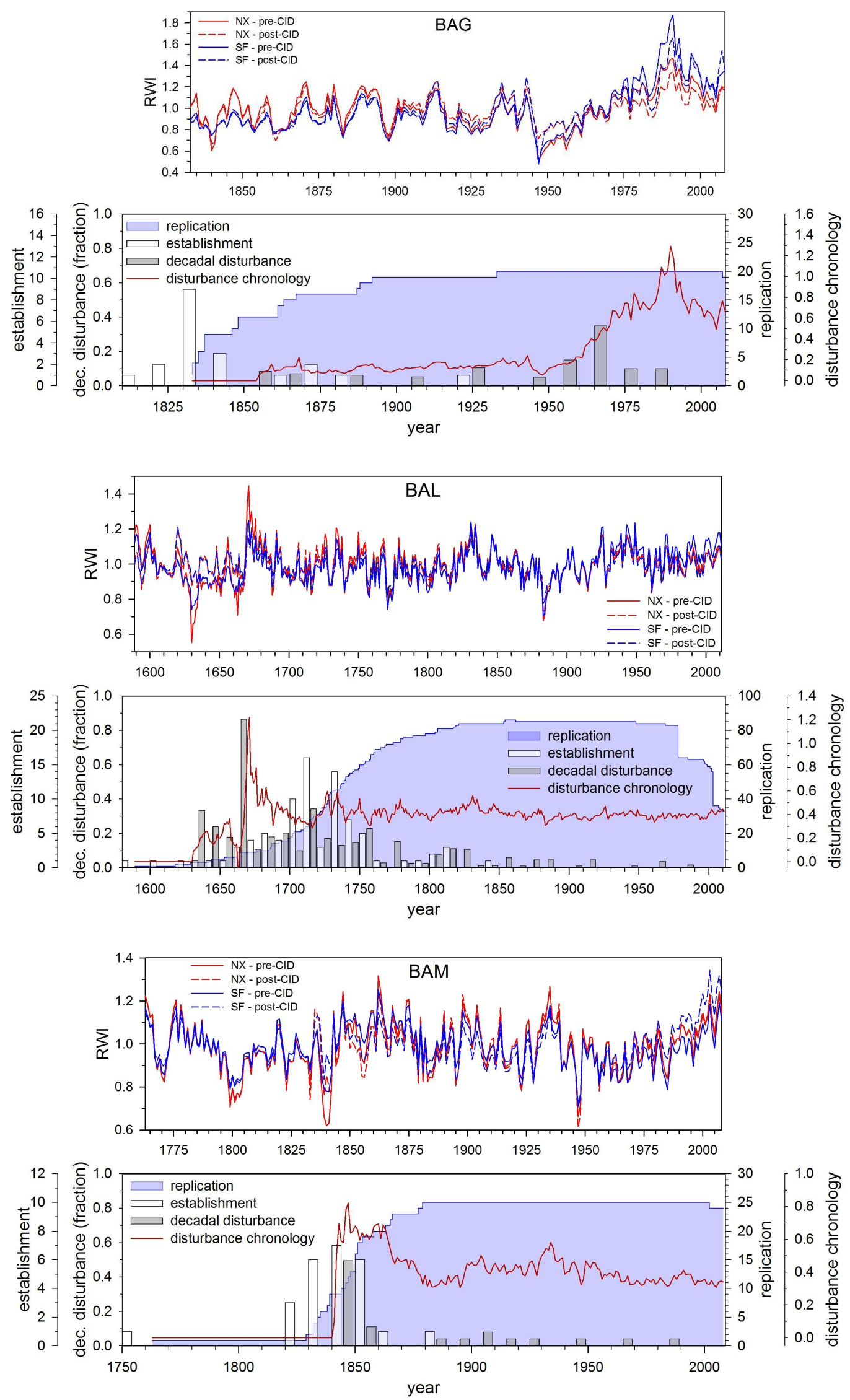

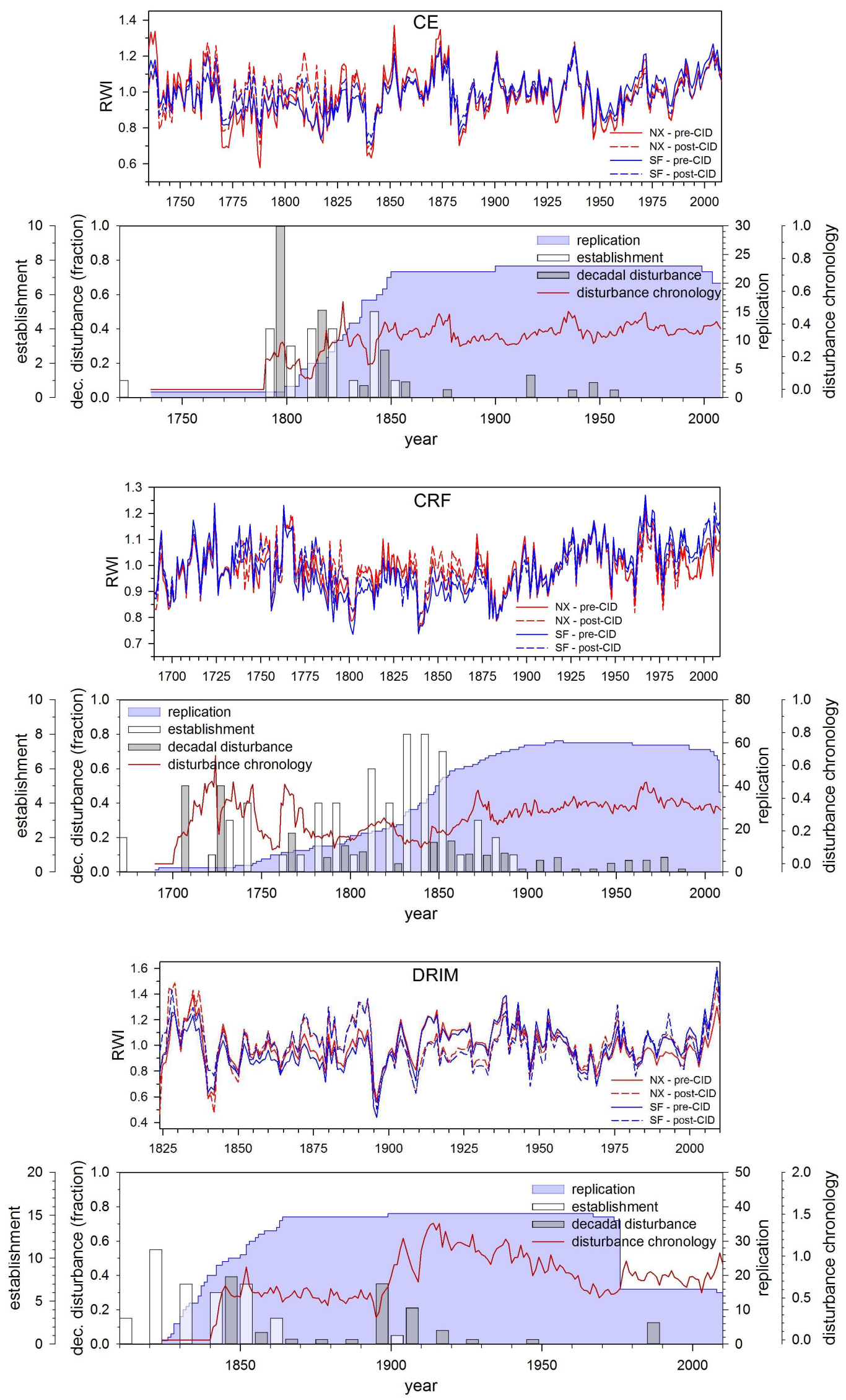

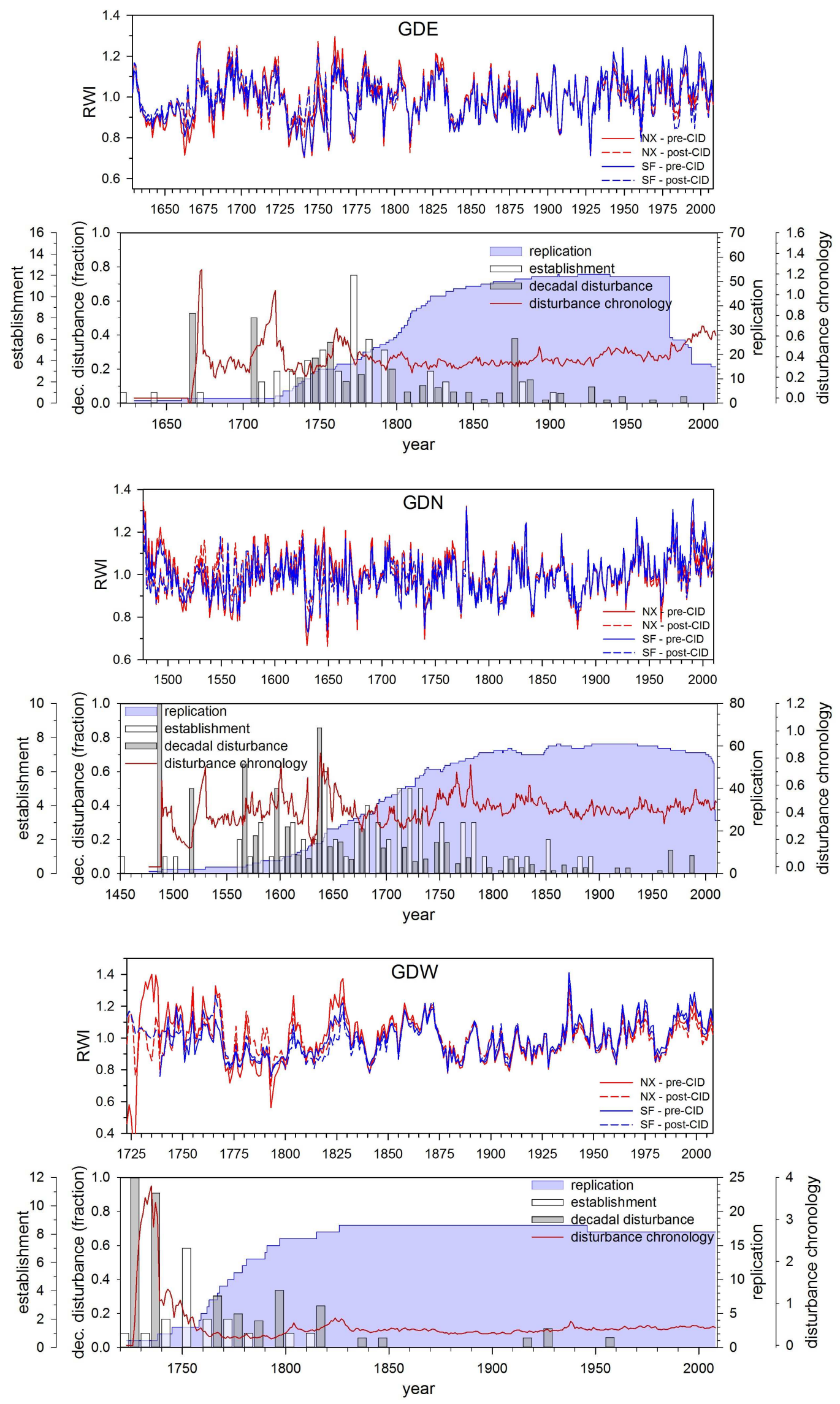

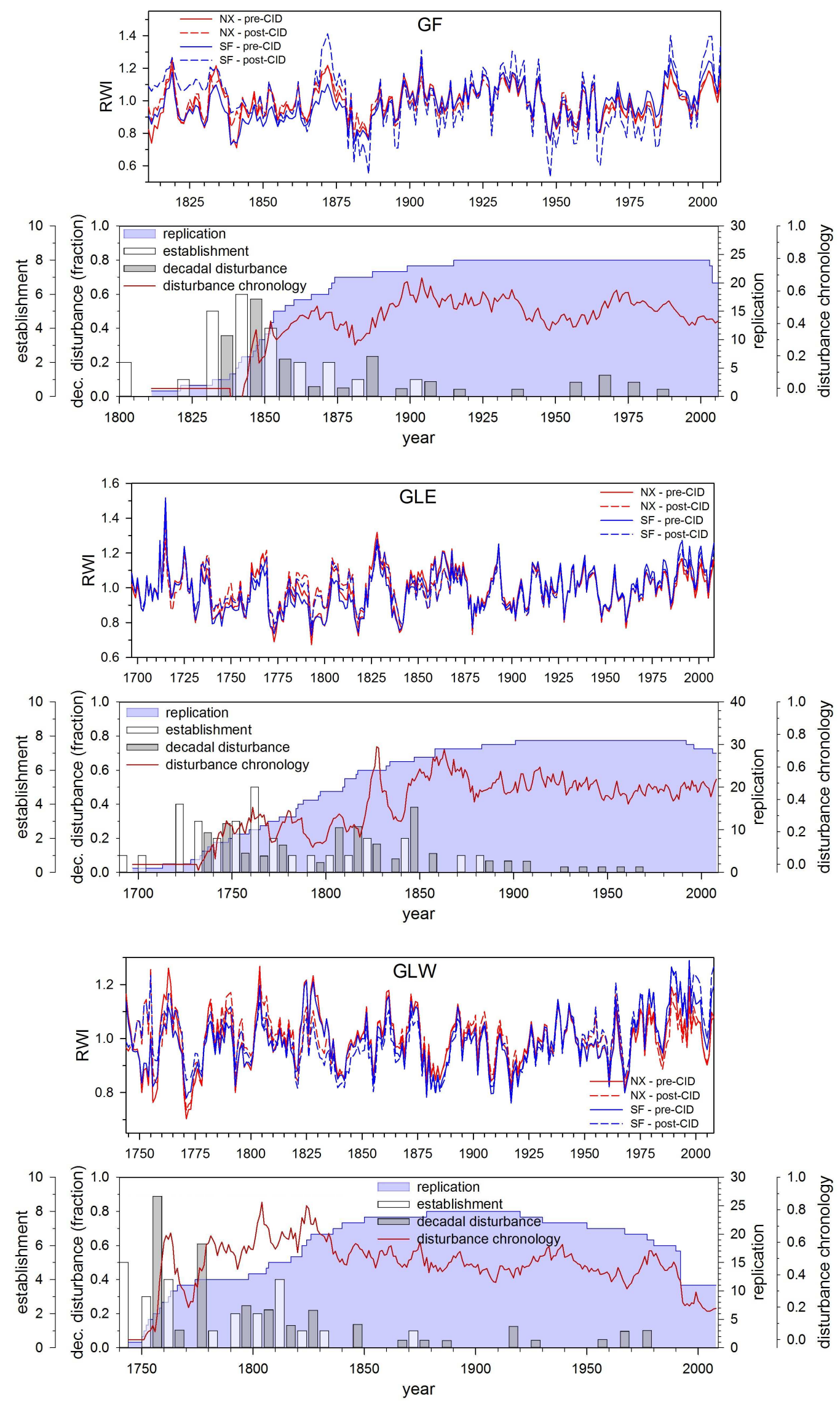

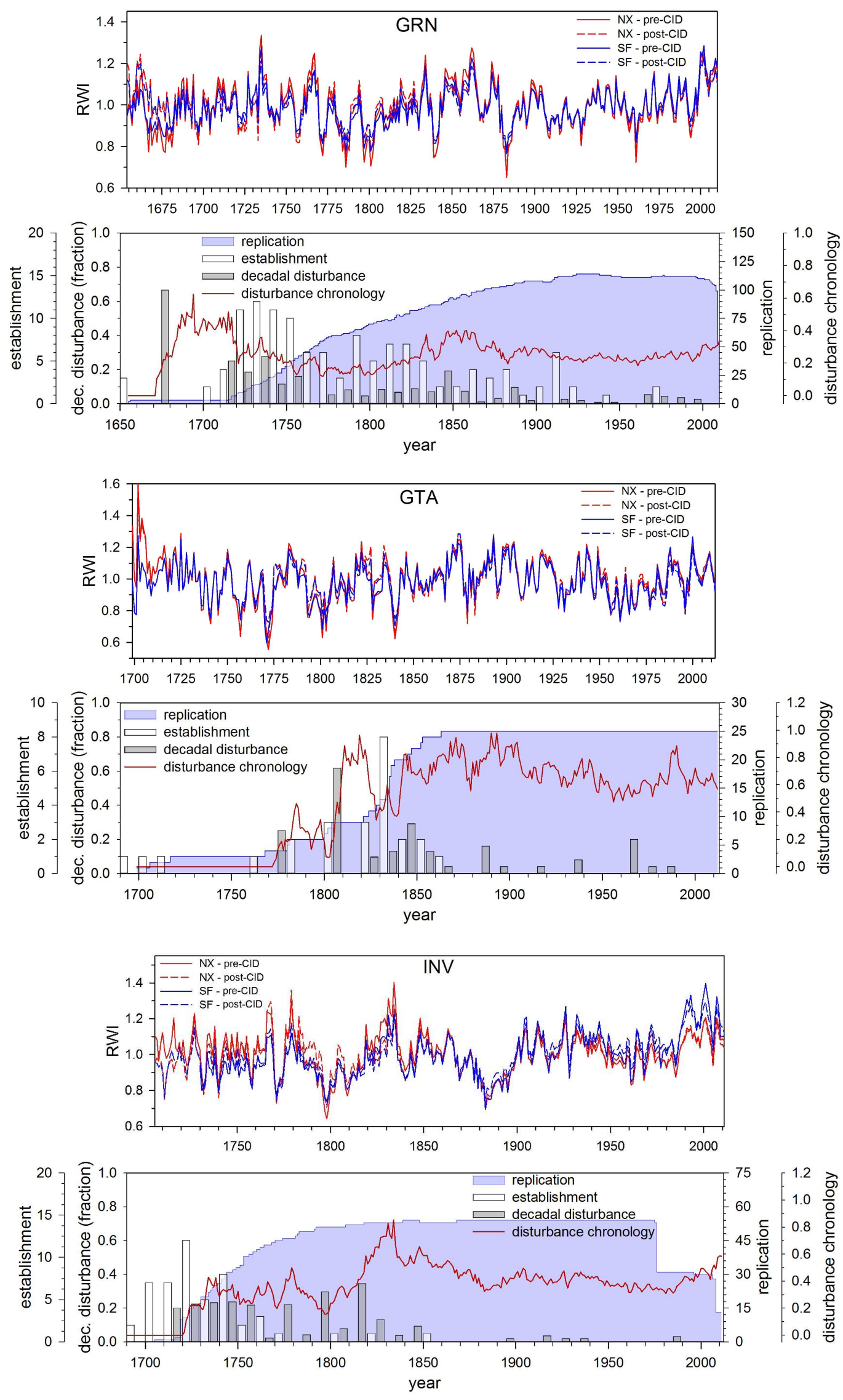

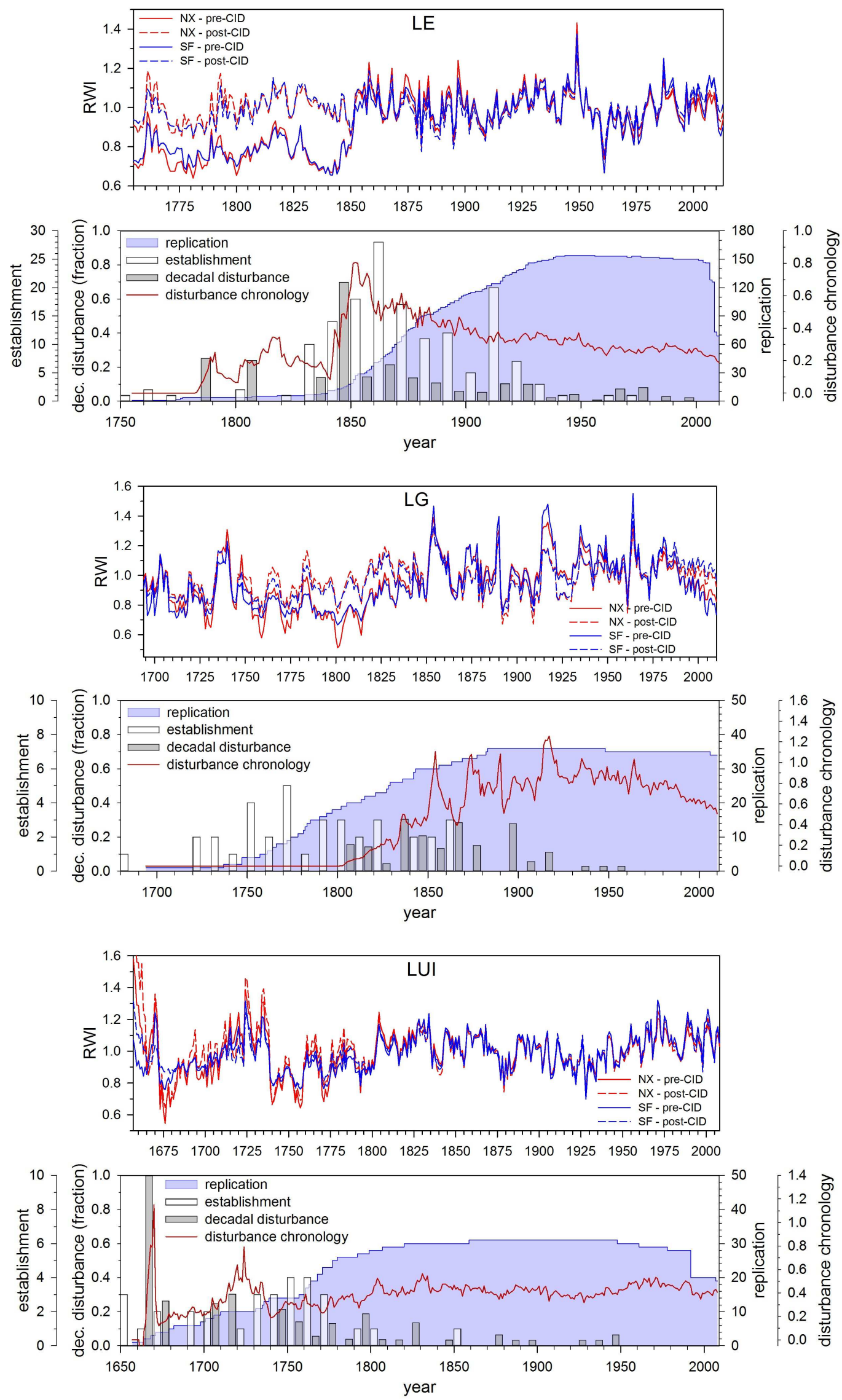

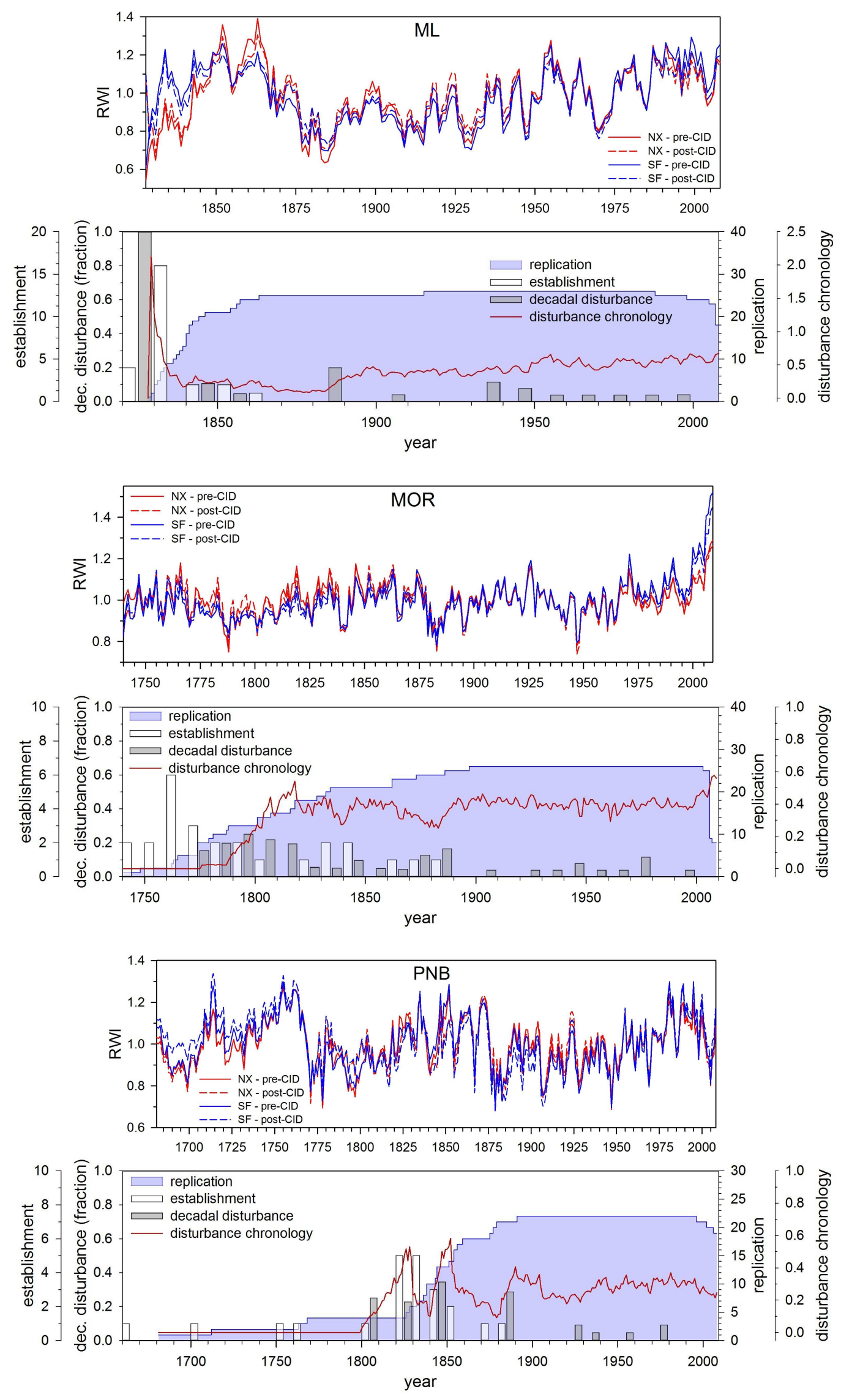

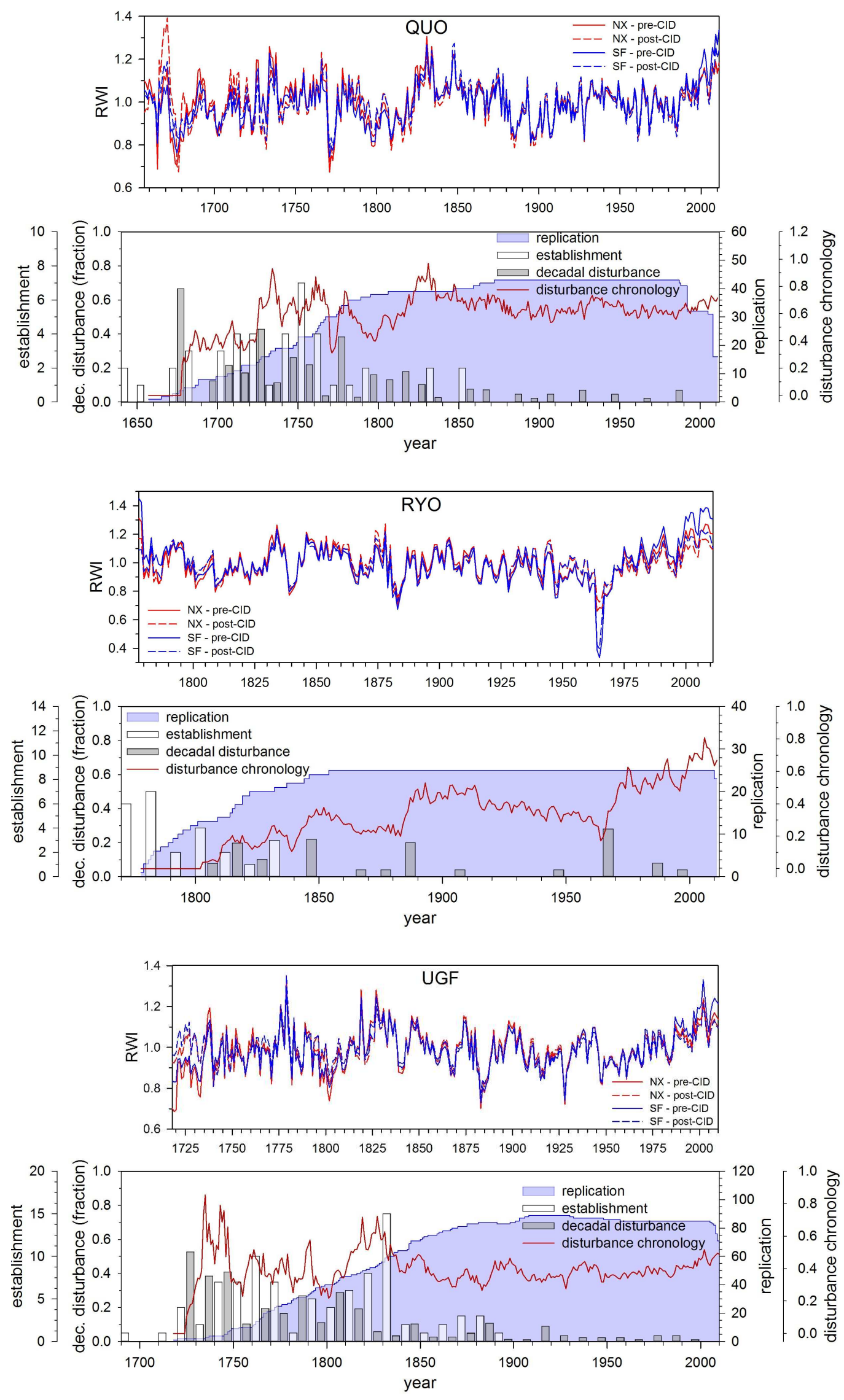
Chronologies before and after CID correction and disturbance chronologies for the West Scotland sites:
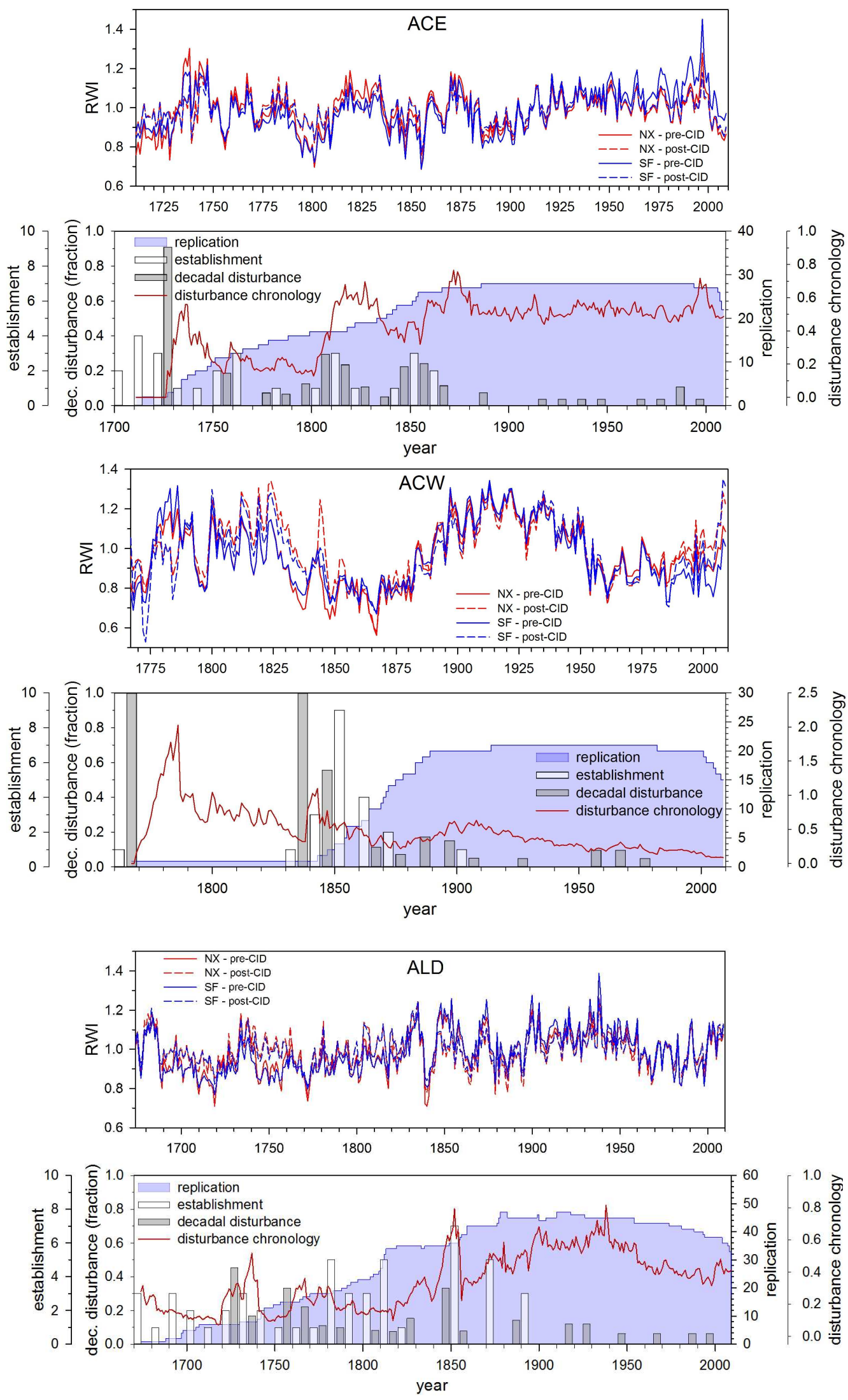

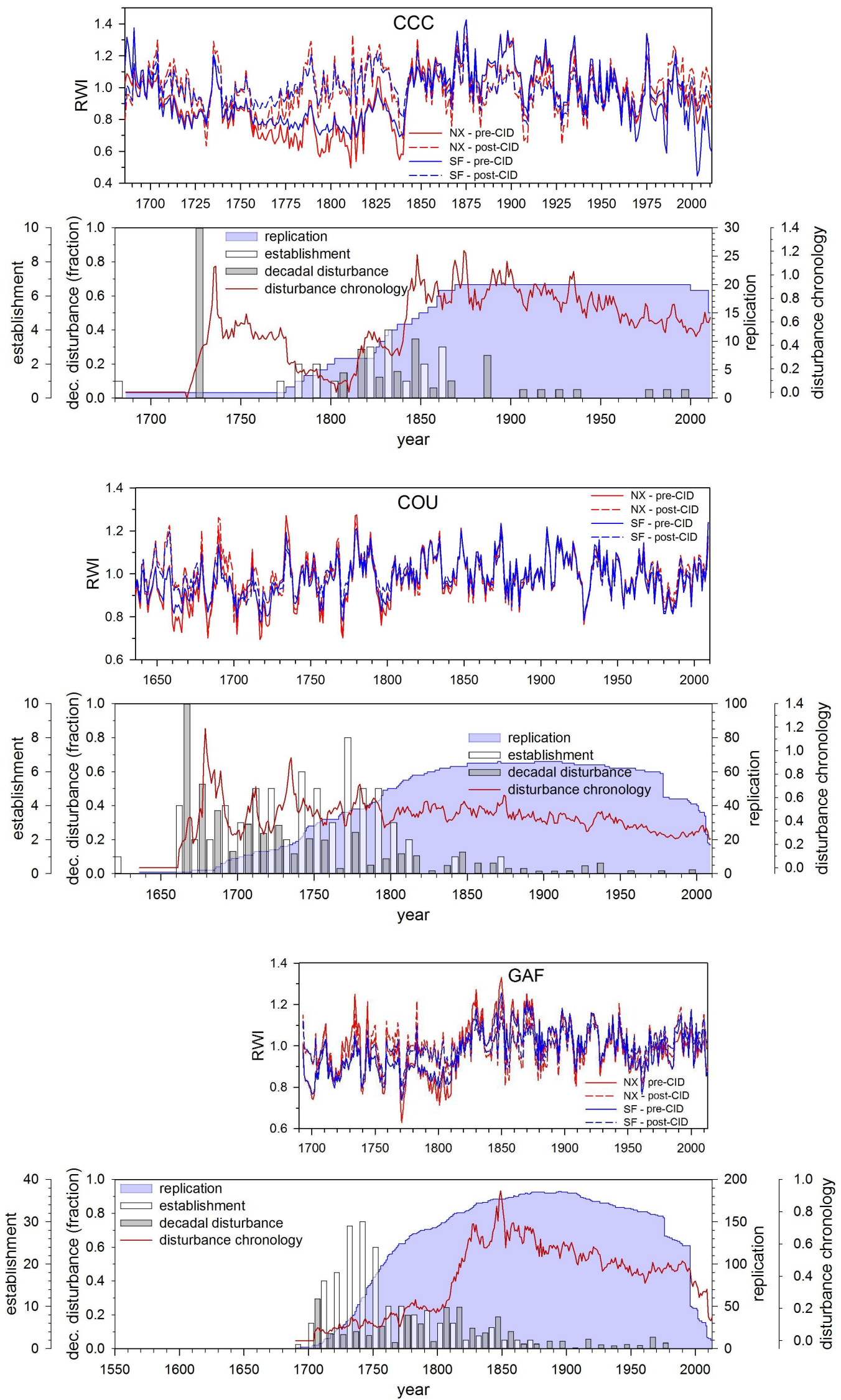

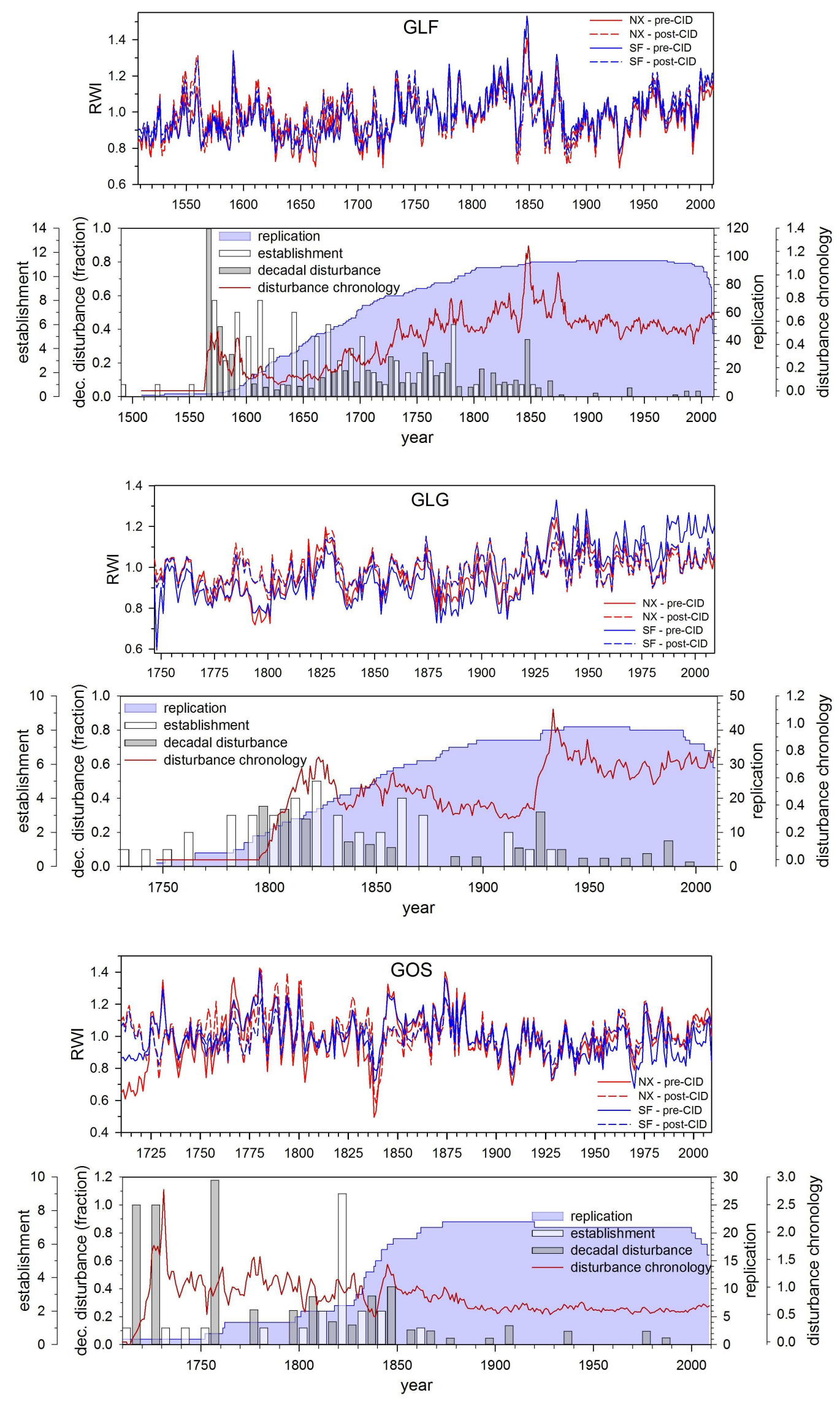

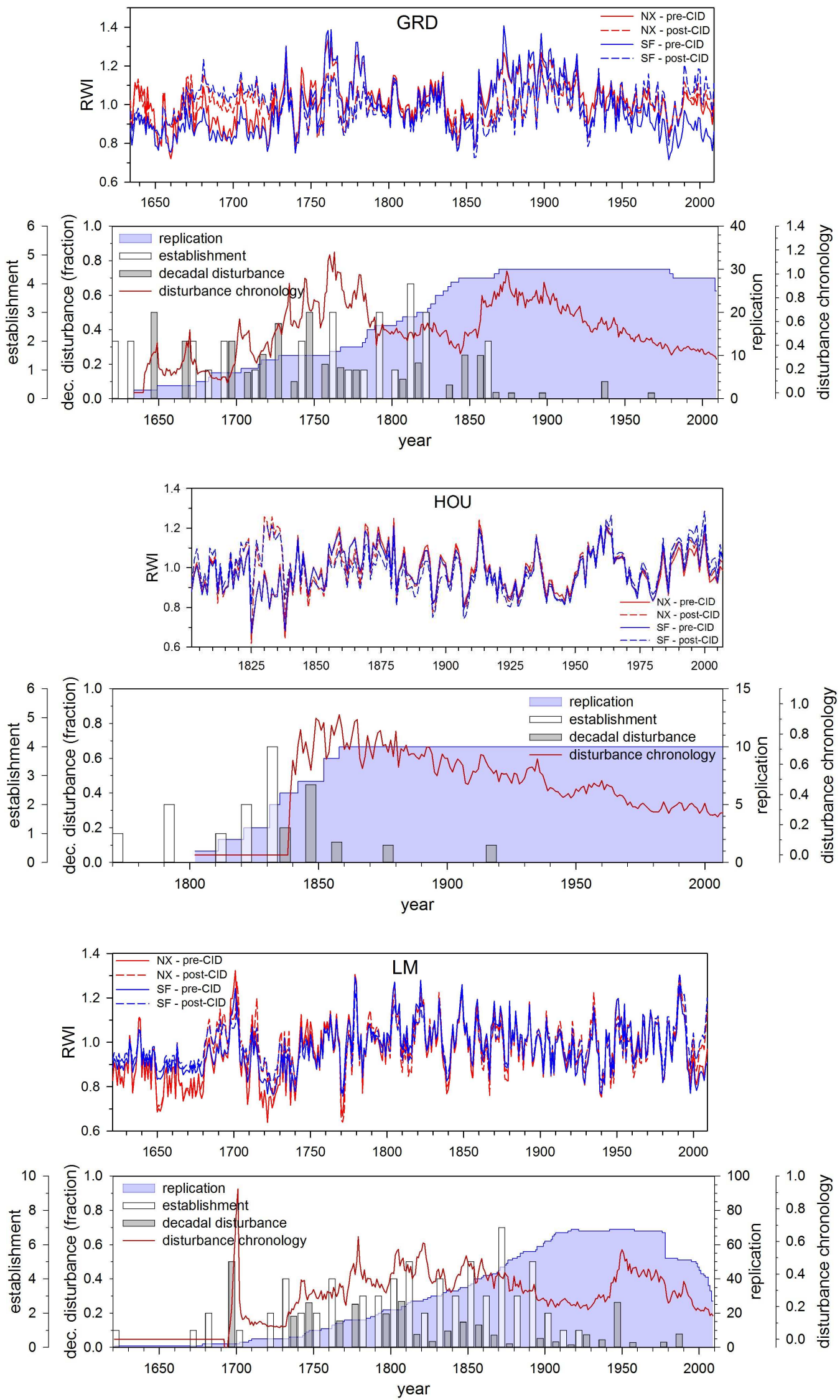

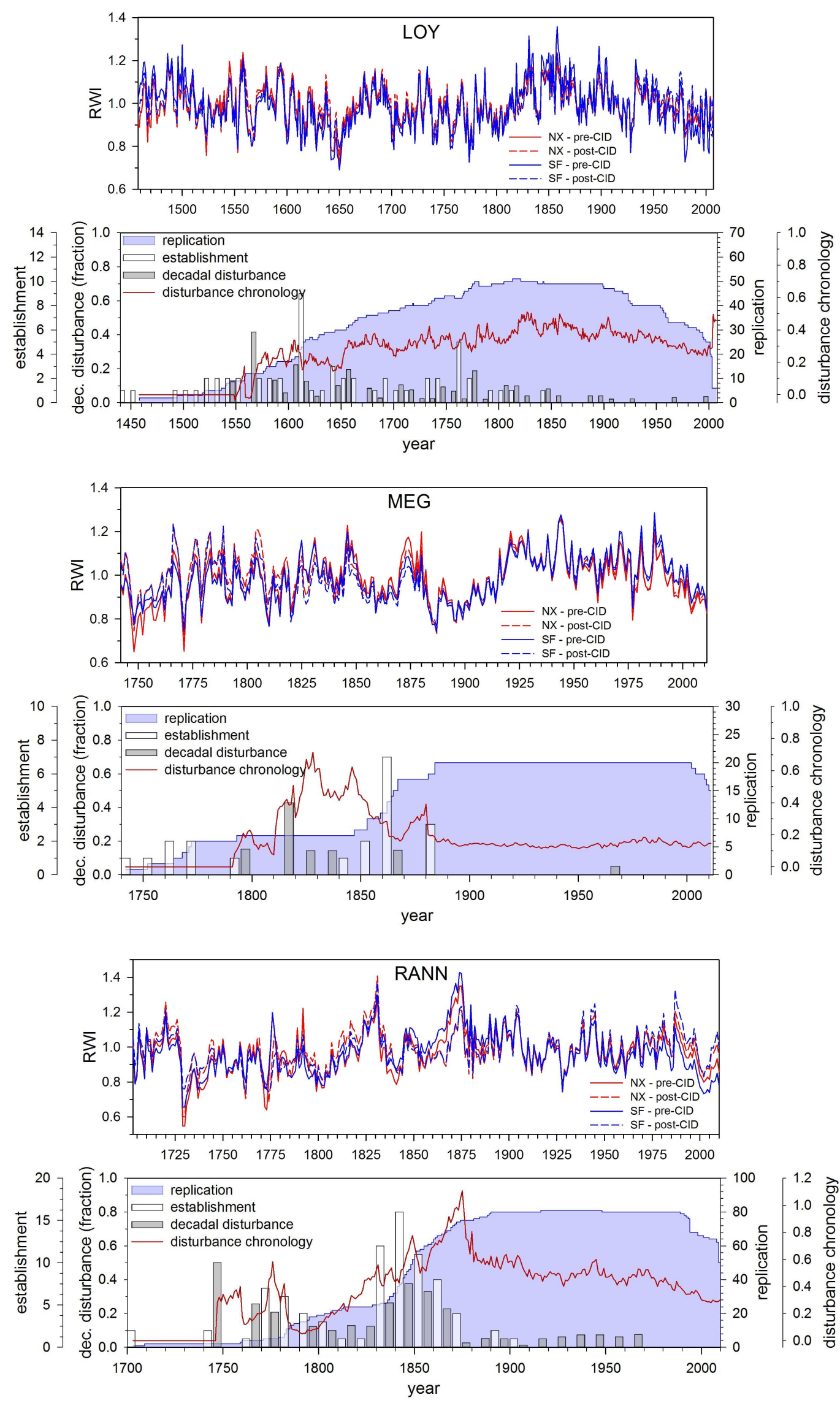

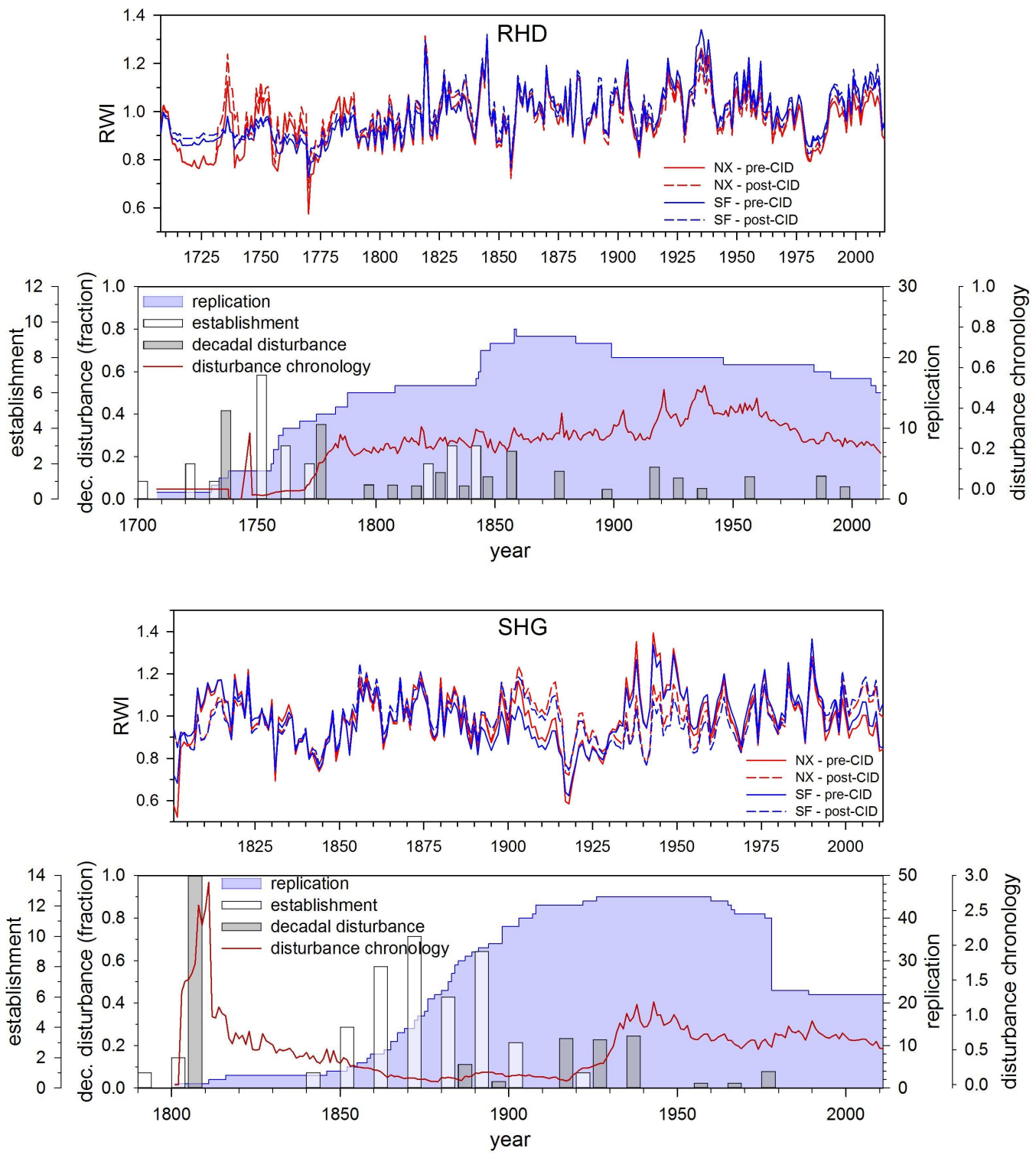